\title{
HOW DEEP IS THE DIFFERENCE?
}

Parsing Difference in the Context of Canadian Diversity Through Documents and Documentary

A thesis paper to support the multimedia installation

\section{Illegal Entries}

By

TARANEH KORKMAZ, BFA

Toronto, Canada June 2019

Presented to Ryerson University

in partial fulfillment of the requirements for the degree of

Master of Fine Arts

in the program of

Documentary Media

Toronto, Ontario, Canada 2019

(CTara Korkmaz 2019 


\begin{abstract}
AUTHOR'S DECLARATION
I hereby declare that I am the sole author of this thesis.

I authorize Ryerson University to lend this thesis to other institutions or individuals for the purpose of scholarly research.
\end{abstract}

\title{
TARANEH KORKMAZ
}

I further authorize Ryerson University to reproduce this thesis by photocopying or by other means, in total or in part, at the request of other institutions or individuals for the purpose of scholarly research.

I understand that my thesis may be made electronically available to the public.

\section{TARANEH KORKMAZ}




\begin{abstract}
This paper follows the blurriness of the concept of difference as it relates to the Canadian idea of diversity, and its manifestation in governmental forms and official documents. It highlights the paradoxical (inconsistent) function of such documents in addressing diversity, individuation and change. This research was informed by the concept of difference, defined (interpreted) by Manuel DeLanda, and is expressed in a multimedia installation titled Illegal Entries, which reconfigures the Canadian Passport Application form (PPTC 153-154) as a threedimensional space. This installation shows viewers that this official document, which operates to legitimize state power over citizens' bodies, is designed to undermine the concept of difference, which is at the core of individuation and is the backbone of diversity and multiculturalism in Canada. This paper provides an account of how a document is transformed into a documentary. The installation creates a bilingual, audio-visual conundrum that consists of institutional texts, commands and warnings. This is juxtaposed with animated graphics, icons and shapes that appear in the document in addition to the image of the passport ID photograph.
\end{abstract}




\section{ACKNOWLEDGEMENTS}

For almost two decades, I wanted to assemble a body of work focused on the experiences of a migrant artist. The Documentary Media program at the Ryerson School of Image Arts opened doors to such an invaluable opportunity. I thank the entire faculty for providing academic resources and financial awards for two years of art-based research practice. Especially Katy McCormick for welcoming me to the documentary world, advising me in the first year and saving many days from the darkness.

In the fulfillment of this Masters Research Project, I owe immense gratitude to many wise, kind, and deserving people for their generous support.

Don Snyder, my companionate thesis supervisor who appreciates artistic freedom more than anyone I've known, and encouraged me to read between the lines, write with more than words, and create beyond imagination. Don illuminated the path for the rest of my artistic journey.

Dr. Izabella Pruska-Oldenhof, my advisor, offered a wealth of creativity and knowledge for me to exploit. Thank you for eloquent conversations about migration, politics, and humanity.

Sara Angelucci, whose expert-filled Master Classes opened the doors to all sorts of artistic inspirations and graciously shared her Aviary insight with me helping the Menagerie do justice for birds' migratory movements.

Dr. Bruno Lessard, the Director of the Documentary Media program and my teacher, provided the French interpretation of Menagerie and offered his ongoing guidance and support for my role in the DocNow 2019 Festival which I had the pleasure of organizing.

I am still looking for words to thank Daniel Clarkson Fisher, whose friendship enriched my life for the past two years. Daniel gifted me with writing the forward for the ESL Poems and elevated my work.

My production assistant and digital artist, Marko Halilovic patiently provided technical support with the installation of Illegal Entries. I look forward to working with you many years to come.

In setting up my thesis exhibition, Illegal Entries, my gratitude extends to Darren Cerkownyk and dear friends; Daniel Schrempf, Kenny McDonald, Emeraude Mbuku, John Verhaeven and Sahar Askary Hemmat.

Finally, and most importantly in advancing my work to the right direction, I greatly benefited from the feedback of my cohort and much-appreciated comments and opinions that I received from Dr. Blake Fitzpatrick, Dr. Brett Story, Vid Ingelevics, Pierre Tremblay, Ruth Kaplan, Dr. Gerda Cammaer and Dr. Dave Kemp.

Thank you all. 


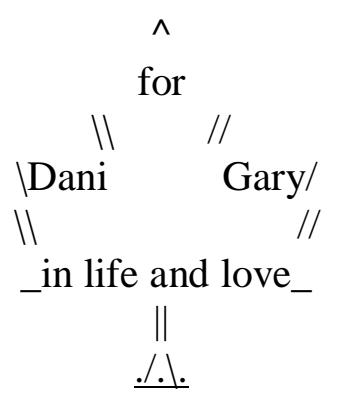

I dedicate this to you both, born continents apart and migrated in one place, my heart. 


\section{Contents}

$\begin{array}{lll}\text { ABSTRACT } & \text { iii }\end{array}$

ACKNOWLEDGEMENTS $\quad$ iv

BACKGROUND $\quad$ ix

1. INTRODUCTION 1

1.1. Current State of Affairs 4

$\begin{array}{ll}\text { 2. RESEARCH } & 7\end{array}$

2.1. Theoretical Frames $\quad 7$

$\begin{array}{ll}\text { 2.2. Diversity and Multiculturalism } & 10\end{array}$

2.3. Documentary in the Expanded Field 11

2.4. Image of The Text 13

3. DOCUMENTARY RELEVANCE 17

3.1. Challenges and Concerns 21

3.2. Points Of Reference 22

3.3. Martha Rosler - The Bowery in Two Inadequate Descriptive Systems (2010) 23

3.4. Jenny Holzer - I Was in Baghdad Ochre Fade (2007) 24

3.5. Barbara Kruger - Your Body is a Battleground (1989) 28

4. METHODOLOGY 32

4.1. The Rationale 32

4.2. Timeline 34

$\begin{array}{ll}\text { Conclusion } & 44\end{array}$

$\begin{array}{ll}\text { Appendices } & 46\end{array}$

$\begin{array}{ll}\text { Bibliography } & 53\end{array}$ 


\section{List of Figures}

1. Screengrab of documentary film Grass: A Nation's Battle for Life, 1925 . $\quad$ x

2. Screengrab of documentary film Grass: A Nation's Battle for Life, 1925.

3. Martha Rosler, The Bowery in Two Inadequate Descriptive Systems, $1974-75 . \quad 23$

4. Jenny Holzer, For New York City, 2005.

5. J. Holzer, Protect Protect, $2007 . \quad 26$

6. J. Holzer, I was in Baghdad, 2007.

7. Tara Korkmaz, Illegal Entries, $2019 . \quad 28$

8. Barbara Kruger, Untitled (Your body is a battleground), 1989.

9. Barbara Kruger, Between Being Born and Dying, 2009.

10. Tara Korkmaz, Screengrab of French text animation, Avertissement, 2018.

11. Tara Korkmaz, Illegal Entries, Test Install, 2018.

12. Tara Korkmaz, pages from Extended Narrative, 2017.

13. Tara Korkmaz, Book, ESL Poems, 2019.

14. Tara Korkmaz, Installation, Illegal Entries, June 2019.

15. Timeline/ Methodology, Vinyl, 117" X 36”, 2019, Listed in Appendix A.

16. Methodology and Process Diagram, 2017-2019, Listed in Appendix A.

17. Questioning the Questions Diagram, 2017-2019, Listed in Appendix A.

18. Passport Application Field, Names, Listed in Appendix B.

19. Passport Application Field, Place of Birth, Listed in Appendix B.

20. Passport Application Field, Date of Travel, Listed in Appendix B.

21. Passport Application Field, Sex, Listed in Appendix B. 
22. Passport Application Field, Natural Eye Color, Listed in Appendix B.

23. Passport Application Field, Height, Listed in Appendix B.

24. Passport Application Field, Current Home Address, Listed in Appendix B.

25. Passport Application Field, Signature, Listed in Appendix B. 
Diversity is given,

but difference is that by which the given is given.

Gilles Deleuze, Difference and Repetition

\section{BACKGROUND}

The undercurrent of my research flows through my intimate experience as an immigrant woman. While it may appear obvious, my personal endeavours are interlaced with socio-political engagement, and they shape my artistic practice. It is clear that such undertakings are ordinary features of democratic fantasies. However, due to the lack of progress in Western democracies, political interests of citizens are often understood as activism, which is not the intention of my paper.

As a member of Bakhtiari ${ }^{1}$ tribe of Iran, negotiating cultural differences has been a reality since my childhood. The Lucky People of the Wind ${ }^{2}$ are nomadic pastoralists migrating each year, thousands of kilometers between their seasonal quarters. Their passage through the changing seasons, and crossing the icy Zard-Kuh³ mountain takes them to green pastures.

To be relevant, one of the earliest romanticized documentary films, Grass, A Nation's Battle for Life $e^{4}$ (1925), is a film I have known all my life, one that claimed to capture the

1. Bakhtiar means "people with luck" in Luri, Kurdish and Farsi.

2. People of the Wind is a documentary film (1976) directed by Anthony Howarth.

3. Located in Zagros Mountains, Iran. https://www.encyclopedia.com/places/asia/middleeastern-physical-geography/zagros.

4. Figure 1\&2: Screengrabs of documentary film Grass: A Nation's Battle for Life (1925) Directed by Merian C. Cooper and Ernest B. Schoedsack. Sourced at: Archive.org”. https://archive.org/details/GrassANationsBattleForLifeBirMilletinYaamMcade. 
Bakhtiari's struggle with biannual migration. As one of the earliest documentaries, Grass was released second after Nanook of the North. ${ }^{5}$ The co-producer Ernest B. Schoensack wrote: "I have always regarded GRASS as a great lost opportunity. There was not enough time or money to do it right." The question is, if there is not enough time or money to do something right, why do it at all?

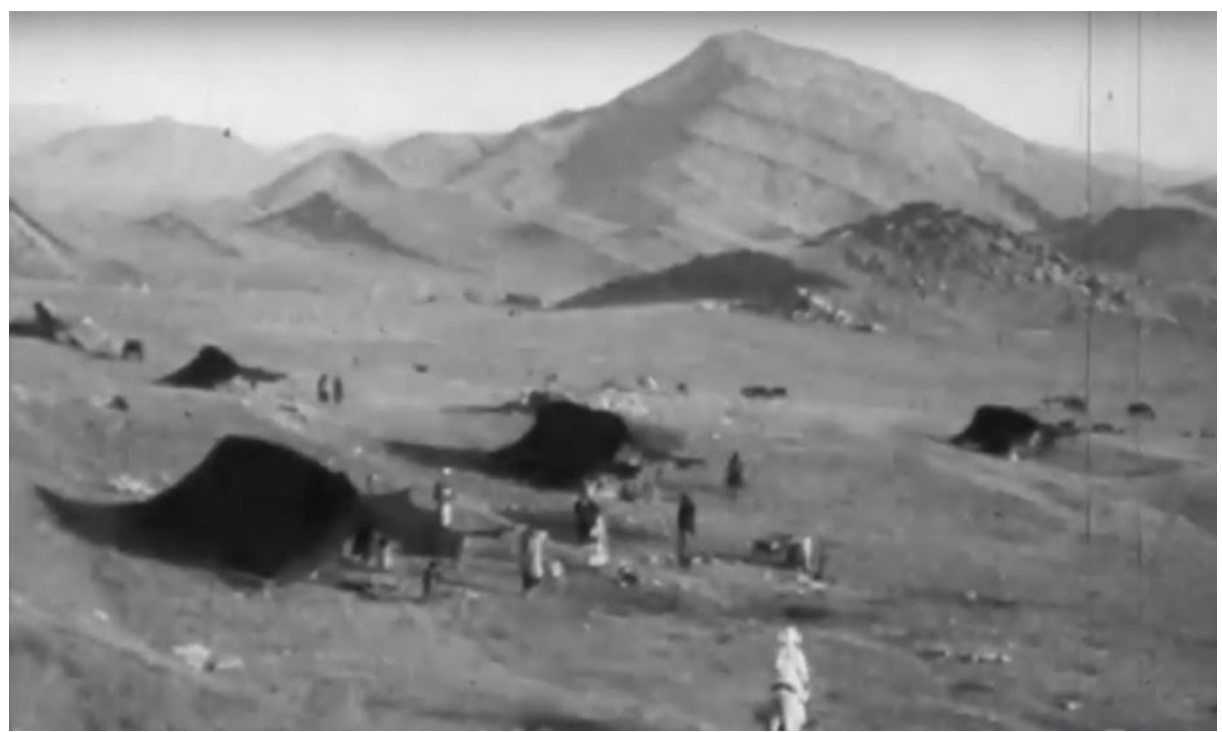

Figure 1: Screengrab of documentary film Grass: A Nation's Battle for Life, 1925.

Even after these admissions it is not clear if Schoenbeck comprehends the meaning of the nomadic motion or the intensity of Bakhtiari migration. Amy Malek points to "flimsily contrived storyline and melodramatic and essentializing intertitles" when describing the film. She speaks of the value of Grass as an ethnographic documentary, a category that in itself is problematic since it views and illustrates difference as spectacle. She writes, "the Bakhtiari are represented through truly ground-breaking cinematography that offers an ethno-graphic contextualization of the migration". However, she admits that "these significant moments are interrupted by Robert Joseph Flaherty. USA. 1922. 
decontextualizing and often comic close-ups and accompanied by distracting and exoticizing intertitles resulting in a melodrama that is incongruous and as condescending to the subjects of the images as it is to the viewers of them."

What is the urge for a documentarian to portray the "other" despite the limitations of frames and language?

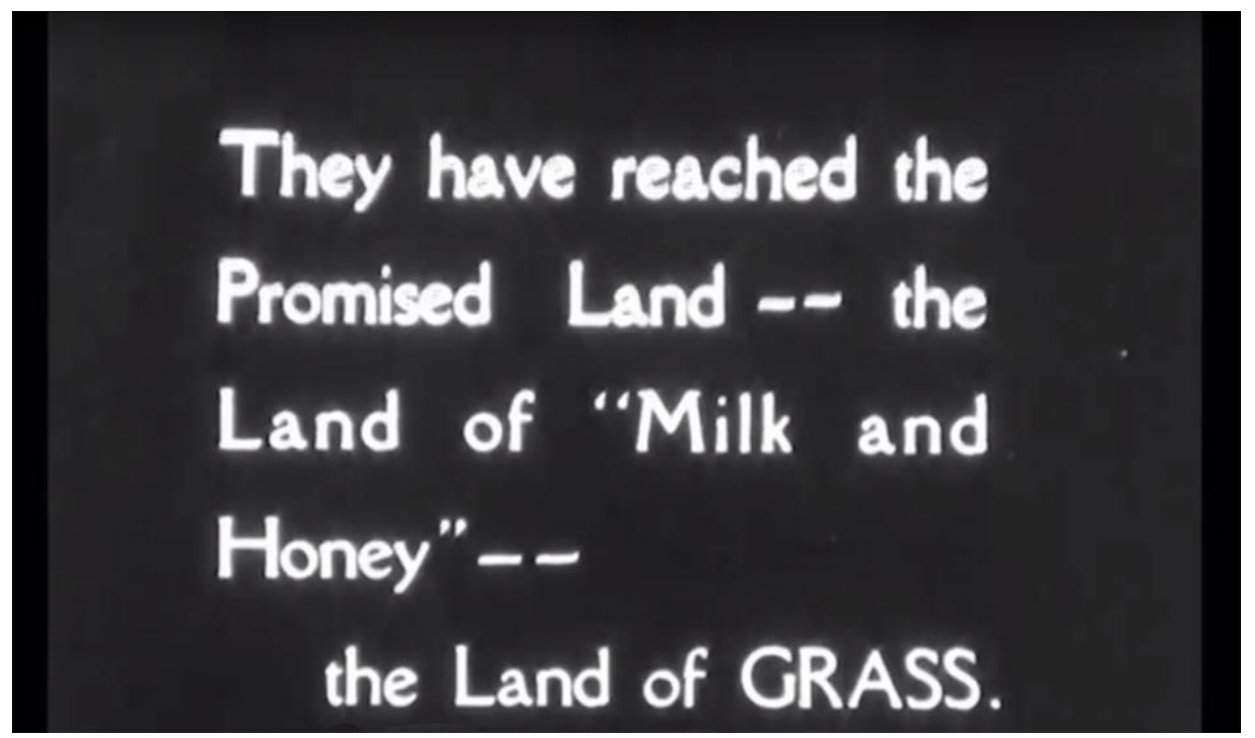

Figure 2. Screengrab of documentary film Grass: A Nation's Battle for Life, 1925.

The second famous documentary about the Bakhtiari tribe was the work of Anthony Howarth, People of the Wind, released in 1972. Malek argues "that despite the fifty years of filmmaking between them, Grass and People of the Wind are actually limited in quite similar ways." ${ }^{77}$ Movies like Grass and People of the Wind, and documentary's deficiencies in general,

6. Amy Malek. "If You'Re Going to Educate 'Em, You'Ve Got to Entertain 'Em Too': An Examination of Representation and Ethnography in Grass and People of the Wind." Iranian Studies: Journal of the International Society for Iranian Studies 44, no. 3 (2011):313-325.

7. Amy Malek. "If You'Re Going to Educate 'Em, You'Ve Got to Entertain 'Em Too': An Examination of Representation and Ethnography in Grass and People of the Wind." 
motivate my project's departure from traditional practices that inadequately and irresponsibly portray cultural differences. ${ }^{8}$

Before leaving Iran, I viewed migration as a positive concept filled with the promise of renewal and change. This was until my family's internal displacement because of the Iran-Iraq war. Refugees of war are not welcomed, even in other parts of their own country. Same as everywhere else, they are ridiculed because of their accents, appearances, and even clothing choices. The supply and demand of employment also turns refugees and migrants into economic threats.

By the mid-1980s, several members of my family had left Iran and were scattered throughout Europe and the USA. I lived in Europe for a decade before migrating to Canada in the mid-1990s. I finally became a Canadian Citizen in the year 2000. This journey took me to many places and I learned other languages. I felt the place of difference in shaping today's world, an experience that now motivates this project and my art in general.

In the deepest sense, all the good things that have happened because of displacement have been eclipsed by the global bureaucratic machine that pins people to invisible walls. Through that lens, the controlling nature of forces and systems designed to restrict the movement of bodies makes travel documents a witness to these violations.

\section{Ernest B Schoedsack, "Grass: The Making of an Epic.” American} Cinematographer LXIV, no. 2 (1983): 40. Schoedsack admits his failure in this article "I have always regarded GRASS as a great lost opportunity. There was not enough time or money to do it right." 


\section{INTRODUCTION}

The common goals and motivations of artists of this generation, as Nicolas Bourriaurd explains, are realized through the process of post-production: "The artistic question is no longer: (what can we make that is new? but (how can we make do with what we have?) In other words, how can we produce singularity and meaning from this chaotic mass of objects, names, and references that constitutes our daily life?"9

To expand on these questions, I learned from the strategy of "Making Do" ${ }^{10}$, which is to redefine the modes of use and consumption, and to re-use and deal with existing things and relations. As such, most of my work transforms banal everyday objects into contemplative environments that reflect the texture of society. One such object is a passport, which is of extraordinary importance in the lives of displaced people such as me.

On that account, the primary subject in my documentary work is the physical document of a passport application. Here, the completed and signed form produces another object, the passport. These devices of "consent and coercion"11 brace the two spheres of state, as Antonio Gramsci determined, the civil and the political, through which governments rationalize and retain

9. Nicolas Bourriaud, Caroline Schneider, and Jeanine Herman. Postproduction: Culture as Screenplay: How Art Reprograms the World. The Use of Objects. ed. New York: Lukas \& Sternberg, 2002.

10. Michel de Certeau. The Practice of Everyday Life. Berkeley: University of California Press, 1984 Web. 16 Jan. 2016.

11. Gramsci, Antonio (2010). Selections from the Prison Notebooks. Edited and translated by Hoare, Quintin \& Nowell Smith, Geoffrey (2010, @1971). New York: International Publishers. 
dominance. Therefore, I take care to stress the historical contexts of power legitimisation through these seemingly mundane objects.

In reviewing the history of the passport in America, Craig Robertson writes, "The historicization of identification documents forces us to consider how it is that we have a come to believe that identity can be documented." 12 My research addresses similar questions and inquires further: how can one official form with a simple design and one poor image ${ }^{13}$ register an individual's true identity?

Robertson illustrates the limiting process of rationalizing information about individuals involved in acquiring passports. He argues, "the documentation of individual identity produces a new identity, one distinct from how people usually talk about themselves." Such documentation cannot verify one objectively or accurately. It is the practice of "the confirmation of a specific identity, one that did not exist prior to the act of documentation and was in fact created in the very act of documentation." He adds "To think of identification practices constituting a regime is to recognize that the appearance of an accurate identity depends on a process of exclusion and marginalization." 14 I want to ask here: who are the people with dual citizenship? Which nationality defines such multilayered beings?

This new identity is often measurable and traceable. Therefore, it must be categorized and sorted according to constructed types or concepts which remove persons from their lived

12. Craig Robertson. The Passport in America: The History of a Document (New York: Oxford University Press, 2010), 11.

13. Hito Steyerl coined the term in 2009 to describe the poor quality of the reproduced photographs. Here I refer to the quality of the photograph that accompanies the passport application and its physical properties. Primarily since Steyerl writes, "The poor image is no longer about the real thing."

14. Robertson, The Passport in America, 11. 
bodies, subjectivities and experiences. As a result, administrative machines equipped with scientific and technical auxiliaries decide the limits of the new identity. From there, the bureaucratic drive to gain knowledge about society provides a utility for the passport as an object of authority, a document with some authenticity and no use for individuality.

To the same extent, and through examination of the historical ties between public administration and political science, Eliza Lee refers to Public Administration as the Science of the State, in a chapter titled as such. This text recounts the ways "public administration has been criticized as consistently producing knowledge that emphasizes control, order and technical rationality at the expense of politics, democracy, participation, and representation." ${ }^{15}$ Lee explains: "liberal reform renovated liberalism by promising a body of objective universal knowledge that would serve as the basis of public authority." She concludes that systemization of such an operation "requires an organizational structure based on the principles of unity of command, hierarchy, control and so forth."16

Passport applications demand biological, cultural, statistical, sociological and other forms of scientific information. These documents were conceived on a positivistic ${ }^{17}$ model of science, which further substantiates itself in requiring the passport photograph. John Berger points to existing scientific links between knowledge and control. He too, underlines that "Photographic

15. Eliza Wing-yee Lee. "Political Science, Public Administration, and the Rise of the American Administrative State. "Public Administration Review 55, no. 6 (1995): 543-44. doi:10.2307/3110345, 544.

\section{Eliza Wing-yee Lee.}

17. John Berger explains connections between positivism and appearance of individuals in Another Way of Telling. (1982) in "Appearances (selections on Positivism)." Connection between photography and positivism is important, which Berger points out in his book. 
information is also fed into systems of social and political control—dossiers, passports, military intelligence." 18

In fact, when a photograph is used scientifically, its unquestionable evidence is an aid in coming to a conclusion: it supplies information within the conceptual framework of an investigation. It supplies a missing detail. When photographs are used in a control system, their evidence is more or less limited to establishing identity and presence. ${ }^{19}$

The photograph section of the passport application affixes this investigative window and provides a void in removing affect. The instruction for achieving such absence includes "neutral facial expression (no smiling, mouth closed). ${ }^{20}$ This is an apparent part of the evolution of legal photographs, through which the individuation becomes unimportant. I return to these remarks in the "Documentary Relevance" section of this paper, where I will refer to Allan Sekula's notes on the archival use of the photograph and its descriptive captions in order to document and categorize bodies.

\subsection{Current State of Affairs}

As the main focus of my research hinges on the concept of difference, the model of diversity in Canada becomes an important question. Diversity is a beacon of hope that brings masses of people to Canada in search of freedom and tolerance. New Canadians from different

18. Berger, Another Way of Telling, 98.

19. Berger, 98.

20. PPTC 153 (07-2017) R2 - Page 6 of 7. 
countries of origin and those who lived in Canada all their lives apply for a Canadian passport to move somewhat freely around the globe.

The process, methodology and content of my project aim to show that difference is more profound than diversity. Without grasping the true meaning of difference, the word diversity gives a vague connotation. It is written and spoken daily but not practiced often or enough. It is imperative to understand that difference is not just a celebratory term but a necessity for achieving positive change, especially in today's social and political climate.

In her book, The House of Difference: Cultural Politics and National Identity in Canada, Eva Mackey writes that in Canada, "State recognition of diversity also limits diversity." ${ }^{21}$ She reviews specific forms of support for the type of diversity that the government would provide and points to government policies clouded by the long-time practice of mainstreaming the idea of British Canadians as the 'norm, that overshadows the 'multicultural' Canadians. The text explores "the institutionalization of difference in national policy and national imaginings." Mackey reaffirms "the key issue here is that despite the proliferation of cultural difference, the power to define, limit and tolerate difference still lies in the hand of the dominant group."22

The current understanding of diversity in Canada plays politics with representation. A Canadian in the passport application is not a man/woman or queer, a homeless person or someone without eyes. Even biological or economical differences are cleaned up in the Canadian

21. Eva Mackey. The House of Difference: Cultural Politics and National Identity in Canada. Vol. 23. Toronto. University of Toronto Press, 2002, 78.

22. Eva Mackey. The House of Difference: Cultural Politics and National Identity in Canada, 70. 
passport application. Is there no place in the application for disabilities? Why would anyone expect deeper diversity echoed in the form? 


\section{RESEARCH}

\subsection{Theoretical Frames and Terminology}

In this section I point to the philosophical and political place of difference in creating an image of diversity and its role in multiculturalism. I also explain how I marry art-historical theories with my documentary work. Finally, I show how text and image, which are the rudiments of documentary media, operate in establishing controlled diversity.

I draw from the philosophical meaning of "difference" 23 and Manuel Delanda's definition of society to theorize my research. In A New Philosophy of Society: Assemblage Theory and Social Complexity, DeLanda expands on the Deleuzian concept of difference and repetition ${ }^{24}$ to explain how assemblages emerge. He proves that assemblages, of any size or structure, are actual entities that come to exist through heterogeneous components. Thus, each society as an assemblage forms and evolves through the changeability or durability of its different components and their relationship to other assemblages.

In an abstract example, an assemblage can be understood in terms of a sentence which does not produce coherence if it consists of the same words. Different words come together to create sense, and they are identified through being different from each other. New words could enter or leave the sentence and new meanings emerge. However, in reality the smallest units of a word, the letters, are only different in appearance. All things in true assemblages, to the smallest quarks and leptons, are heterogenous particles. And this is the nature of all that exists and

23. Gilles Deleuze (1987)"Difference is not diversity. Diversity is given, but difference is that by which the given is given" Deleuze explains: "Every diversity and every change refers to a difference which is sufficient reason.", 222.

24. Deleuze writes: "everything which happens and everything which appears is correlated with orders of differences: differences of level, temperature, pressure, tension, potential, differences of intensity.", 222. 
functions. All emergences occur through the movement of different component of each assemblage. Culture, identity or economy are larger, social examples that result from such transactions and thrive through the force of difference.

The connection between citizenship (and immigration, refugee, and statelessness) and difference exists because of a preoccupation with the movement of bodies, including the bodies aching for belonging and inclusion. The question is not how to include people in our nation if they are not like us, but rather why should they be like us in order to be with us? The state's struggle with difference is because difference counters hegemony, which is obsessed with norms and the status quo ${ }^{25}$. Control and governance of society through archaic disciplinary systems has worked for centuries. How long will that last in light of expanding heterogenic assemblages that emerge through global migrations and displacements?

Under the umbrella of difference, this project also covers how government data and digitization processes imbed conditions such as "addressability" and "locatability" within Canadian Identity. In Playing the Identity Card, Louise Ammore explains the extent of these investigative terms in the identification of citizens by modern states. The chapter "Governing by Identity" reinforces the main argument critiques in this paper of how identifiers such as a postal code or date of birth simplify the identified people and their socio-cultural geography. Such systematic dilution of a citizens' differences threatens their individual and private existence.

In the face of this kind of governing by identity, to call the comfort of identity into question would mean constructing a more fully fleshed out form of privacy. One that does not deploy the private as a means of distancing the other and shoring up our

\footnotetext{
25. Gramsci links maintaining "the status quo" to political hegemony in his Prison Notebooks.
} 
identity position, but instead asks that privacy be possible in the very public spaces that demands 'who are you?' It is not so much lack of privacy that is the political problematic, but rather a lack of social space in which we can see and be seen, engage with differences and difficulties of our world. ${ }^{26}$

Institutional control of identity also fails to grasp that "At stake in contemporary programmes of identification is, then, the very mobility of identity itself. Because by now we are all familiar with idea of identity as something that is never finally fixed, and it is in the process of identification."27 Lammore's chapter also links the history of addressability to military logistical knowledge and commercial supply. It concludes, "The technologies that have made possible a global supply chain of export processing zones and off shore sites, are simultaneously being embedded into border crossing cards, visas, passports and immigrant ID that includes mobile people within governable space by means of their targeted exclusion."28

My installation Illegal Entries reflects on this problem. It is no secret that the military psyche thrives on uniformity and similitude to establish obedience. It has always benefited from technology and science for implementation of power. Underpinned by science, the influence of a military mindset on this type of law and regularity control indeed "depoliticizes the positioning of our identities" as Lammore concludes. The struggles of individual bodies, their politics and differences, are replaced with data, information, and technology.

26. Colin J Bennett. and David Lyon. Playing the Identity Card: Surveillance, Security and Identification in Global Perspective. London, New York. Routledge, 2008. P29-36.

27. Colin J Bennett and David Lyon, 28.

28. Louise Ammore, 31. 
Essentially, themes of cultural diversity, language, displacement, and individuation become more transparent when viewed through the lens of difference. This concept needs to be fully understood as a positive force that promotes social inclusion. Such an argument materializes in the strategies and processes involved in deconstructing a government application as an art object and re-purposing it as a space that echoes individual voices.

Here, however, data, text, and technology counter their intended use in legal control. The structure of the text, the image used in the passport application, and the physical object of the passport itself contradict their original purposes.

\subsection{Diversity and Multiculturalism}

My project exposes governmental and institutional forms as work tools for systems of evaluation and control, which normalize the homogenized Western discourse driven by its hegemony. The aim is to examine and reveal how these forms undermine the inter-cultural nature of contemporary Canadian society, specifically through reductive methods of categorizing people into fillable fields and checkboxes and ignoring their differences. Reconstruction of the application form in space filled with fragments of the body explores the "imagined" ${ }^{29}$ Canadian citizen, this time underlining differences instead of sameness and homogeny.

The actions of my work disrupt the order and coherence of the official form by separating all fields into individual pieces, then activating each field through a different approach to text and image such as video, sound, animation and even poetry. The main strategy is to avoid

29. Benedict Anderson, R. O'G. Imagined Communities: Reflections on the Origin and Spread of Nationalism. Rev. ed. Verso, 2006. 37- 47. Anderson argues that nations are socially constructed and therefore imagined communities. He explains how the convergence of capitalism and diversity of the human language created the possibilities of new forms of imagined communities as the basis for the modern nations. 
answering the question in the expected format, or providing the raw information that the field is requesting. The responses to each question are constructed in ways that reflect the realities of a complex, diverse and so-called "multicultural society" by not providing the quantifiable, oneword short answers that identify and confine a living person in a database grid and statistic.

\subsection{Documentary in the Expanded Field}

As social media and its "crowd-created" visual work enter the documentary landscape, the need for more powerful truth increases. Currently, the proliferation of social media and usergenerated content plays politics with truth. As a result, taking anything as fact calls for conviction beyond photography and text. By their nature, images are complicit in all sorts of exaggerations and deceptions. Subjectivity and the need for personal satisfaction or pure artistic creativity are only some of the less harmful intentions that taint the objectivity of images. Therefore, new methodologies and vanguard aesthetics bring openness and add interest to documentary art.

As an installation artist, I like to look back at the history of sculpture, when a parallel dullness surrounded the field of sculpture in the ' 80 s and when the plinth became an institutionalized limb attached to statuary. Back then, sculptural art became relevant only if landed on such a device. As a result, the field of sculpture expanded "through the representation of its own material or the process of its construction." 30 The move beyond the domain of sculpture aligned with the "situation of postmodernism, a practice (that) is not defined in relation to a given medium - sculpture — but rather in relation to the logical operations on a set of cultural

30. Rosalind Krauss, "Sculpture in the Expanded Field." October 8 (1979): 31-44. doi:10.2307/778224. 
terms, for which any medium—photography, books, lines on walls, mirrors, or sculpture itselfmight be used." ${ }^{31}$

The foundation of monuments shattered when sculptures stepped down from the plinth and walked out to the world. Documentary also needs to continue to evolve via such societal encounters with film and photography. On that account, I borrow the term "expanded field" 32 from the history of the art installation. Traversing documentary practice and sculpture piqued my interest to look beyond film and photography. In the expanded field, the documentary is not limited to time-based imagery. Its reliance on words and images takes alternative turns, which will be discussed in the documentary relevance chapter.

My installation, Illegal Entries draws viewers deep inside the passport application form and the application process itself. It changes all fields in the application form into a threedimensional space that surrounds the viewer. The sound component of the installation takes shape through a synthetic voice that reads the instructions and warnings in the form. The visual components consist of animated icons from the application, silent video performances of the passport photograph that respond to the audio readings, and short video narrations.

The fact that the subject of this documentary is an inanimate object (an application form, which "has a certain shape that is constant and does not change") ${ }^{33}$ removes it further from

31. Rosalind Krauss, "Sculpture in the Expanded Field.", 42.

32. A term Rosalind Krauss uses to describe postmodern sculpture and installation practices.

33. Nicolas Bourriaud, Caroline Schneider, and Jeanine Herman. Postproduction: Culture as Screenplay: How Art Reprograms the World. The Use of Objects. ed. New York: Lukas \& Sternberg, 2002. 
mainstream documentary practice. The object's importance and purpose exist in relation to the space it occupies, and the work focuses on that. There is no storyline, no temporal progression.

\subsection{Image of The Text}

Traditionally in documentary practice, image and text complemented one-another. Text juxtaposed with images creates more clarity and generates additional meanings. More recently, artists such as Martha Rosler utilize text to provoke thoughts. Instead of documenting the faces of social problems, she believes that words do a better job of triggering critical thinking in the individuals who interact with the images on display.

The installation Illegal Entries asks, "How Deep Is the Difference?” It strategically treats the text as an image to create a visual experience that disrupts its intended meaning. In the journal article "Image as Insight: Visual Images in Practice-Based Research,” Lisa Marshal writes that "the contrast of language and vision leads to an appreciation of vision as a cognitive modality with its own capacities to construct and convey knowledge and concepts." ${ }^{34}$ The link between language and knowledge, the established connection between words and their meaning are creative elements that produce what Roland Barthes calls an "image reservoir" within us.

In The Pleasure of Text, Barthes also underlines the "split" between language and text, and he points to difference as something that is achieved as a positive attribute of the text's impact on the reader. ${ }^{35}$ Barthes writes, "Whenever I attempt to (analyze) a text which has given me pleasure, it is not my (subjectivity) I encounter but my (individuality), the given which makes

34. Lisa Marshal, "Image as Insight: Visual Images in Practice-Based Research.” Studies in Art Education 49, no. 1 (2007): 23-41. http://www.jstor.org/stable/25475852.

35. Roland Barthes, The Pleasure of the Text. Trans. Robert Miller. New York: Hill and Wang, 1975. 
my body separate from other bodies and appropriates its suffering or its pleasure." 36 The text has the ability to individuate the reader's place in the context of what is being read.

The embodiment of "difference" in materials and images taken from an application form creates an alternative visual experience than simply reading the form. This experience is "through give and take between eye, mind, materials, and forms..." ${ }^{37}$ It is therefore corporal and entangled with affect. The application's design and purpose intentionally detach the applicant from emotion and affect.

Language in an institutional context has a different utility, compared to its communal context. The same words exchanged in communal discussion and friendly promises can be used to construct "command[s] to do something [:] a subordinate is held responsible for the fulfilment of the command, and punished for disobeying it." 38 The design of applications and forms caters to a "system of reading" 39 that is deterministic (not differential) and expects a specific outcome. Therefore, these forms cannot amend the concept of difference.

DeLanda refers to this as "linguistic acts that create social obligations." Such assemblages of words form "commands" to create the bond "to do something" between the bodies acting upon the texts. Forms and applications are objects (tools) that governments use to control or monitor their citizens. Completing institutional forms separates fragments of persons

36. Barthes, The Pleasure of the Text, 62.

37. Marshal, Image as Insight, 5.

38. DeLanda, Assemblage Theory, 4.

39. Barthes, The Pleasure of the Text, 12. 
from their bodies in order to fit them into acceptable norms. Text (language) therefore is an active tool in Gramsci's concept of coercion and consent.

In the passport application form such linguistic acts appear in a hybrid of questionnaire, commands and warning notices. The installation Illegal Entries highlights these distinctions and reflects different tones that appear through font variations, which I will explain in detail in the methodology section of this paper.

It is also important to point out the lack of diversity in the implementation of text and language in the immigration system. Both the immigration apparatus and its ally, language (text) confuse difference with opposition. Masny and Waterhouse emphasize Deleuze's definition of state power that rests "on the exercise of binary machines which run through us and the abstract machine that over-codes us." ${ }^{40}$ In their critique of mapping of Canadian (and Australian) immigration policies, they believe binary categories such as official/unofficial language and citizen/non-citizen are to "draw rigid molar lines through government immigration policy and delimit the status of an individual." ${ }^{41}$ Deleuze speaks of molar $^{42}$ as "molded and organized"

40. Diana Masny and Monica Waterhouse. "Capitalism, Immigration, Language and Literacy: Mapping a Politicized Reading of a Policy Assemblage." Policy Futures in Education 14, no. 7 (2016): 1005-1019.

41. Diana Masny and Monica Waterhouse, 1013.

42. Gilles Deleuze, Félix Guattari, and Brian Massumi. A Thousand Plateaus: Capitalism and Schizophrenia (Minneapolis: University of Minnesota Press, 1987), 195. "Not only are the great molar aggregates segmented (States, institutions, classes), but so are people as elements of an aggregate, as are feelings as relations between people; they are segmented, not in such a way as to disturb or disperse, but on the contrary to ensure and control the identity of each agency, including personal identity." 
amongst other elements that colonize or territorialize the forces of consciousness and extract a (bad) conscience.

Ultimately, all binary machines repress difference as an agent for opposition and negation, instead of catalyst for intensity that ignites affects and individuation. Such apparatuses utilize data and text tirelessly, as in the case of the application form. Difference is a compass for change, as it is as decisive between day and night. However, it is never entirely day or absolutely night. The night is a day in the process of becoming through the differences in time, and vice versa. More importantly, each night and day, despite their repeated patterns, are never the same. 


\section{DOCUMENTARY RELEVANCE}

I aimed to find some answers to the question "How Deep Is the Difference?" through the installation Illegal Entries, which aligns with documentary practice on many levels. Primarily, by presenting a document as a documentary, my work leans on a counter-practice plateau. Given the involvement of the passport application form, it connects with the kind of documentary works that address critical issues through the re-appropriation of text and image. To some extent, I am also engaging with creative approaches to such media as put forward in Martha Rosler's and Jenny Holzer's work, and Barbara Kruger's installations.

Some sections of the installation Illegal Entries can fall into the performative mode of documentary practice. Acts of folding the printed application form into a paper airplane, reading poetic text, ${ }^{43}$ and instances of people re-enacting their passport photo experiences are at the core of this project, and "[raise] questions about what is knowledge. What besides factual information goes into our understanding?" These instances of performativity "induce an 'aha' effect, where we grasp a principal structure at work, and are impelled to take a deeper look." ${ }^{\prime 4}$

In explaining the counter-practice claim, a passport application is, in fact, a controlled interview that is not interested in a unique story. It is not interested in tension and is not equipped to deal with individual cases or micro-histories. ${ }^{45}$ Instead, it works as an autobiographic

43. I am referring to the text Menagerie, inserted Appendix C, in which I use voice over a short video transforming the signature field of the application.

44. Bill Nichols, "What Types of Documentary Are There?" in Introduction to Documentary. Bloomington, Indiana: Indiana University Press, 2001. P. 130-131.

45. Douglas Harper. "Talking about Pictures: A Case for Photo Elicitation." Visual Studies 17, no. 1 (2002): 13-26. With referring to Harper's account of micro-histories I want to also point to the fact that the passport document acts as an anti-documentary. 
documentary that does not require sensory awareness, ${ }^{46}$ despite the fact that it is used to identify millions of unique individuals.

In addition, the passport application photograph must say as little as possible about the person. The nature of the photograph is to provide the least amount of information regarding the applicant's social/cultural history and lived experiences: it's an image separated from time and place, captured in a white space, it follows a standardized pose, and it expresses no emotion-it thus ceases to be an image. It becomes a form of ascriptive data that supports other statistics in a document that registers similitude.

Traditionally, the use of language is an integral part of documentary practice. In forms of written and spoken text, voice, subtitles or text interlace stories and information with documentary film and photography. In my research, I focused on text to underline the concept of difference and to read into the attempts to erase what outside the norm. I don't use it to explain the image or talk about facts. I either question the intention of the text or I treat it as a counterimage of its meaning.

Pertaining to text and image, historically, the pairing of the data and the legal photograph creates a "more extensive social body" as Allan Sekula outlines in The Body and the Archive. He reflects on the methods of biosocial pathology, which assists in the ownership of government and policing over individual bodies. Sekula explains the "double system" within photographic portraiture as "a system of representation capable of functioning both honorifically and repressively." He argues that "Photography came to establish and delimit the terrain of the other,

46. Harper, “Talking about pictures”, 692. 
to define both the generalized look-the typology and the contingent instances of deviance-and social pathology."47

To date, Sekula's account of the biopolitics of othering through photography allows for criminalization and archiving all sort of inadequate bodies; from those who fail to acquire work, to those who look different and those who move around too much. Why is a Canadian passport application interested in this information? Can one be Canadian without a document tracking gender, age, height, address and the face of a person? How does a documented Canadian feel? Honored, or repressed and controlled? How does an undocumented Canadian feel? Where does such a person live?

The use of a document is not uncommon in documentary practice. However, documents usually serve as supporting material for the promise of truth: textual documentation and various forms of photo elicitation add corporeal information (different kinds of information) $)^{48}$ to a story, to activate different dimensions of the human consciousness. ${ }^{49}$ My project, however, deconstructs the document in order to reveal the actual truth of it. It looks at the document's context and content. It questions the role of this object in a contradictory system of power that says one thing and acts in the opposite manner, where erasure replaces elicitation.

Martha Rosler warns documentarians about text and image in her photo-essay The Bowery in Two Inadequate Descriptive Systems, since both fail to reveal the truth about societal

47. Allan Sekula, “The Body and the Archive." October 39 (1986): 3-64. doi:10.2307/778312.

48. Harper, "Talking about pictures".

49. Harper. 
issues without exaggeration, exploitation or evocation of pity for the participants. Literature, cinema and mass media reproduce and consume these systems.

Jenny Holzer's intervention in the secret documents of the US Government also utilizes text documents in a documentary installation to entice the audience to "read" into a systemic erasure. In her work I Was in Baghdad Ochre Fade (2007), which will be discussed in the next section, she recreates sworn statements of torture and interrogation committed by the US Government in oil paintings on linen panels. These hidden letter-size pages become a large-scale installation. The concealed document then is impossible to disregard.

There are also situations where a text or word becomes an image. In the context of capitalist "production and distribution", the term "diversity" works as such an image: overused and cliché. Likewise, Barbara Kruger parodies the methods of consumption in contemporary society. In her installations that will be discussed in this paper in this paper, she uses an excess of text in a large format, eye-catching fonts and iconized images from magazines to counter the modes of capitalist consumption.

Lastly, as mentioned earlier, the visual manifestation of my project is an intersection of sculpture and installation, and aims to investigate the document as an object and space, as well as questions its usage. While the "[s]implicity of shape does not necessarily equate with simplicity of experience" 50 in relation to creating an image for a particular system of power, the simplicity of an object, such as the passport application, overshadows its intricacy and the challenges of acquiring it.

50. Robert Morris, Notes on Sculpture, 228. 


\subsection{Challenges and Concerns}

My project challenges the association with truth of documentary practice by demonstrating the contradictory function of a "document." It questions the effectiveness and inadequacy of "descriptive systems," 51 such as image and text employed in the documentary realm. Further, the project takes note of the photograph's honorific and repressive role mentioned by Alan Sekula, and the concept of the "poor image" 52 coined and investigated by Hito Steyerl. With all that, the aim is to question the truth about one's identity as portrayed in a Canadian passport photo.

As for the notion of truth, the passport application is a legal document designed to funnel people into a complex and multicultural society. However, it can only do so by reducing them to simple entities measured and judged according to basic data and imposed standards.

Therefore, this project deliberately chooses to focus on the ironic transformation of a document into a documentary. Specifically, it asks: how can one universal document with a simplistic design speak to the public discourse of Canadian-ness? How can a simple text and one low resolution (poor) image ${ }^{53}$ register an individual's true identity? Does the political system believe in diversity or is it just asking its citizens to "act" 54 in a way that reinforces a perception of what diversity is?

51. Martha Rosler's terminology - Rosler acknowledges the failure of photography in addressing social pain in a dignifying manner.

52. Hito Steyerl coined this term to describe the deficient qualities of the digitally reproduced image such as JPG or AVI. "It is passed on as a lure, a decoy, an index, or as a reminder of its former visual self." She underlines.

53. Hito Steyerl, “In Defense of the Poor Image." E-flux Journal \#10, 2019. (November),1-9.

54. Referring to the Canadian Multiculturalism Act, 1988, which lays out a set of rules as to how citizen should perform. 


\subsection{Points of Reference}

As mentioned earlier, my research combines personal and professional pursuits. It links my experience with multiculturalism and difference ${ }^{55}$ to a variety of artistic explorations. As an artist, the urge to create innovative works and make a different type of documentary inspires the structure of my research. Also, challenging the persistent images of documentary and the normative knowledge of what documentary is, motivates a distinct departure from them.

In reviewing historical developments of documentary practice, Bill Nichols argues that each mode of documentary representation arises in part through a growing sense of dissatisfaction with a previous mode. ${ }^{56}$ In that same spirit, through this project, I want to participate in the reshaping of the meaning of documentary. Yet by no means is the claim here that the end result creates a brand-new mode of documentary.

Lastly, ethical issues around the artist-subject relationship have shaken my foundational perceptions about documentary practice. To some extent, I relate to Nichols's notion of dissatisfaction and I question whether it is possible to create documentary work that addresses people's place in today's complex society without taking advantage of their personal struggles. To be more specific, my research aims to reveal the problems with diversity and multiculturalism without invasive probing of various cultures. 2004.

55. Gilles Deleuze and Paul Patton. Difference and Repetition. London: Continuum,

56. Bill Nichols explains in What Types of Documentary Are There?, 119. "We do well to take with a grain of salt any claims that a new mode advances the art of cinema and captures aspects of the world never before possible. What changes is the mode of representation, not the quality or ultimate status of the representation." 


\subsection{Martha Rosler}

Since its inception, documentary practice has faced an ongoing critique of generalizing social struggles and victimizing its subjects. One of the most prominent voices against such practices is Martha Rosler. In her work, The Bowery in Two Inadequate Descriptive Systems (Figure 3), ${ }^{57}$ she asks viewers to decode the connection between capitalism and the criminalization of poverty. In addressing social problems, Rosler responds to the alcohol addiction problem in Manhattan through combinations or pairings of image and text. She chooses to portray social pain not on the faces of people, but through space, objects and language. The absence of agonized bodies, rather than pitiful portrayals, render Rosler's work more powerful.

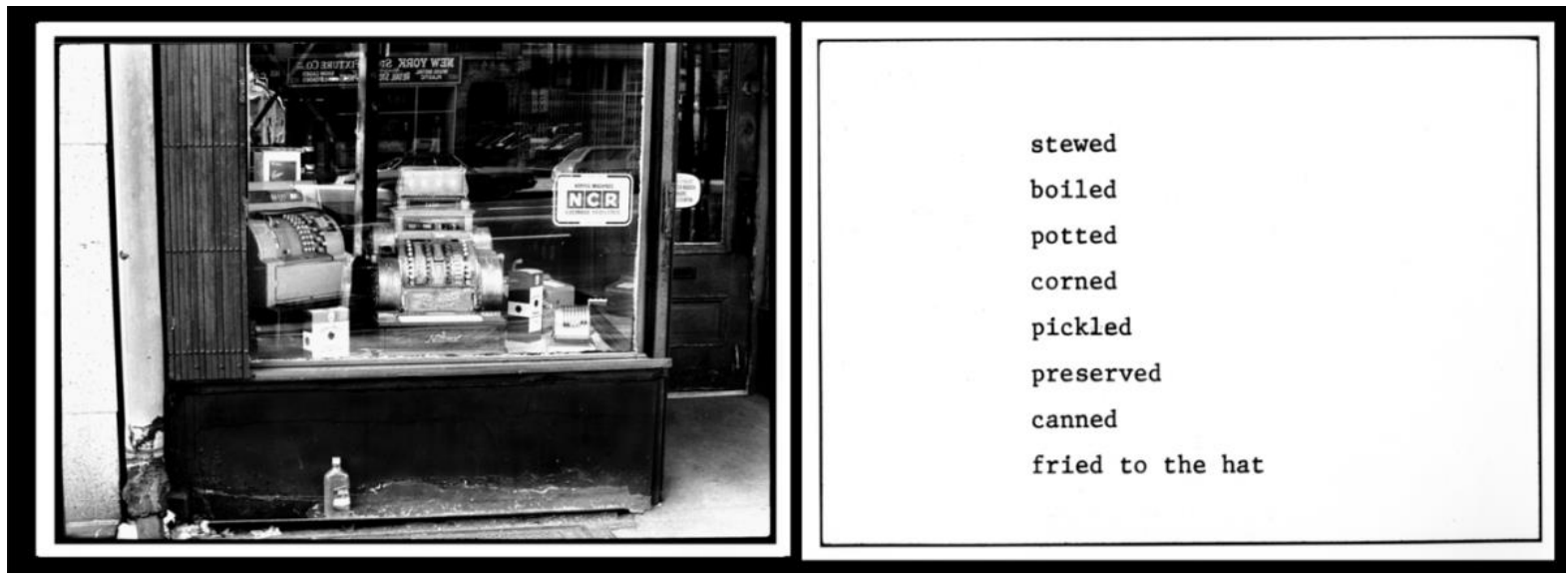

Figure 3. Martha Rosler, The Bowery in Two Inadequate Descriptive Systems, 1974-75.

I take inspiration from Rosler's work to discuss socio-cultural themes outside the photographic norms and to look for new ways that can move documentary towards alternative

57. Steve Edward. Martha Rosler: The Bowery in Two Inadequate Descriptive Systems. London: Afterall Books, 2012. 
"descriptive systems." My work is interested in Rosler's critique of the "poverty of representation", which avoids using text as caption or explanation and image as evidence for mainstream commentaries.

The two descriptive systems Rosler believes have been representing the truth poorly are text and photograph. She believes that documentary practice must use these two systems more ethically and creatively. Instead of showing the faces of poor people, she chooses to expose the spaces of poverty hidden in certain neighbourhoods. Rather than using text to narrate or interpret the image she juxtaposes the image with carefully thought-out and arranged words that make the viewer search for an explanation of the true cause of poverty. She provokes a different way of looking for discovering a deeper root. I also enjoy the irony that she frames in words such as "canned" and "corned" and their cloaked meanings.

Text and image are also active components of generalization through the reductive system of inquiry and identification of individuals in the passport application. Repeatedly, the same restrictive format of text and image places people within a nation that advertises freedom and difference to the rest of the world.

\subsection{Jenny Holzer}

The relationship between government documents and public domain ties this research to Jenney Holzer's artistic practice. The integration of text, image and object in her installations, and the public dimensions of Holzer's work, are important to this project. Her textual work occurs in various spaces that are predominantly public. ${ }^{58}$

\section{See figure 4.}

Jennyholzer.com. "Projections". https://projects.jennyholzer.com/projections/new-york2005/gallery\#9. 


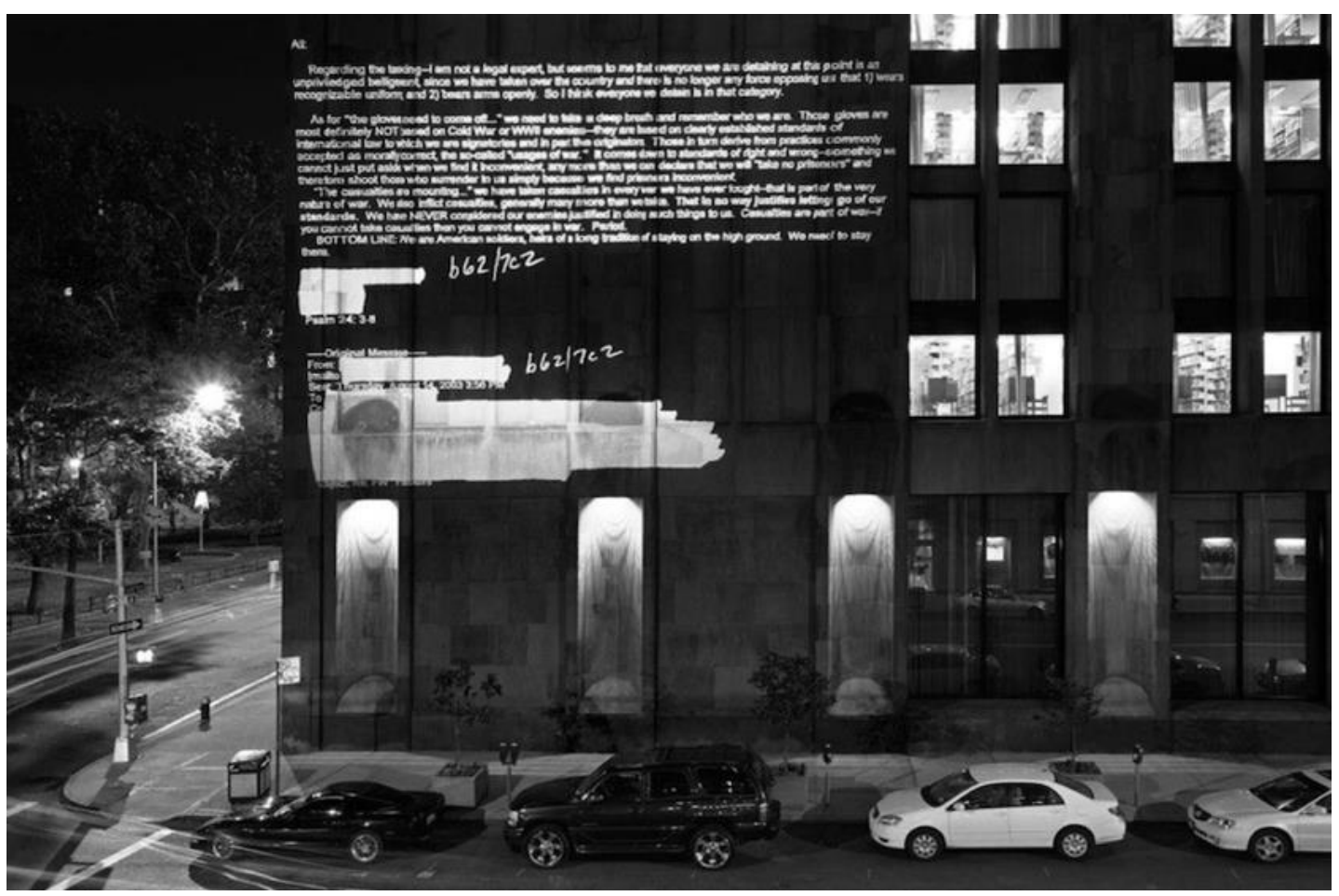

Figure 4. Jenny Holzer, For New York City, 2005.

However, in contrast to Holzer, the public nature of my research arises from the document's domain, that is, people's private and individual lives. Although it gathers personal and private information from the applicants, the document asks the same questions from everyone applying for a Canadian passport. It works as the government's administration of the most simplistic idea of citizenship by carbon-copying its citizens to traces of what they are. Here, a simple analysis of the word "public" invokes a doubtful meaning. Is public about all the people or a term to funnel normative narratives and social wholesaling?

Holzer's re-appropriation of the US government briefing for invading Iraq ${ }^{59}$ and letters concerning torture and confessions of US army soldiers who committed crimes in Abu Ghraib are examples of various texts that she uses in her artwork. With important details blacked out,

59. Figures 5, Massmoca.org. "Deeper Look: Jenny Holzer I Was in Baghdad Protect Protect.”. https://massmoca.org/event/deeper-look-jenny-holzer-protect-protect/. 
these documents exist passively in the public domain as a declassified information. Holzer's reappropriation sheds light upon the erasure rooted in the practices of governing institutions.

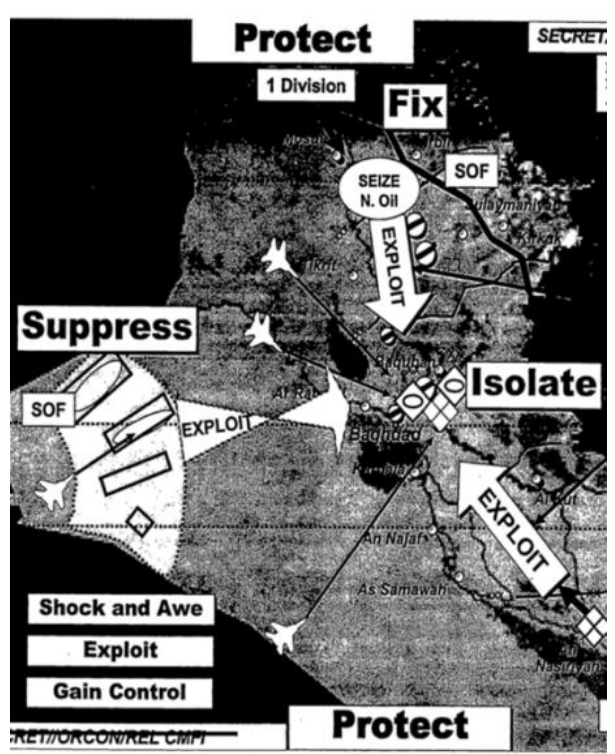

Figure 5. J. Holzer, Protect Protect, 2007.

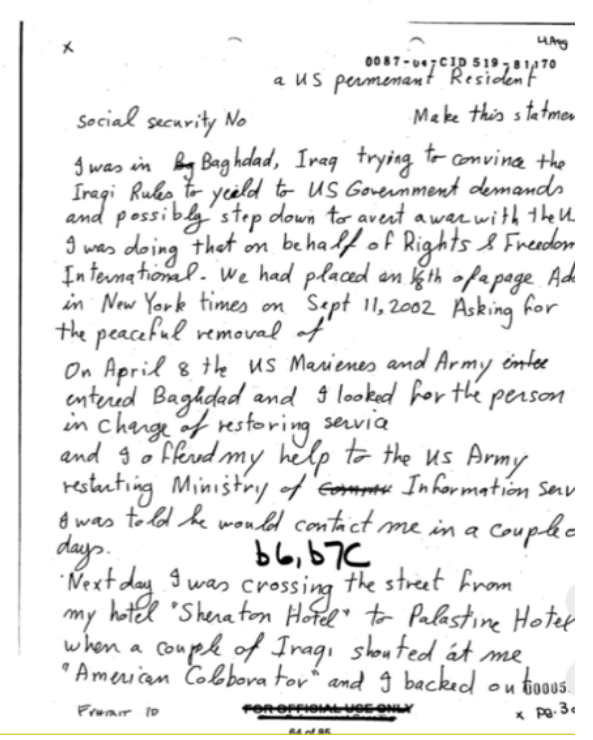

Figure 6. J. Holzer, I was in Baghdad, 2007.

Systemic erasures appear in many of Holzer's documentary installations. In I Was in Baghdad Ochre Fade (2007), it is visible in the act of blacking out of the text. In the form (PPTC 153) the erasure occurs through reductive questioning, threatening tone and restrictive entries.

The text in Holzer's work consists of secret documents not accessible to ordinary people. She reveals dark secrets through these hidden documents. I Was in Baghdad Ochre Fade $(2007)^{60}$ is a series of oil on linen transcriptions of descriptions of torture. Documents from the Iraq War were used in her Redaction Paintings (2009), which were created using recently-

60. Figures 5, Massmoca.org. "Deeper Look: Jenny Holzer I Was in Baghdad”. https://massmoca.org/event/deeper-look-jenny-holzer-i-was-in-baghdad/. 
released classified memos with texts redacted by censors; and an installation in the lobby of 7 World Trade Center is another way Holzer repurposes secret government documents.

In order to see the erasing power of these devised forms and their strategic design to reduce people to abstractions, the installation Illegal Entries invites viewers to step inside the document. They are not just looking at the document anymore - they become part of the object itself. They are objectified.

Robert Morris elaborates on such experience: "The smaller the object the closer one approaches it and, therefore, it has correspondingly less of a spatial field in which to exist for the viewer. It is this necessary greater distance of the object in space from our bodies, in order that it be seen at all, that structures the non-personal or public mode." ${ }^{61}$ The public display and augmentation of the text used in these forms can create an overwhelming response. In addition to magnification, Holzer also relies on LED lights and projection for her text installations. At times she uses the aesthetics of commercial signs and neon color to enhance the visual experience. Her use of irony induces confusion. What resembles signage is in reality a statement or phrase from declassified government documents.

A similar treatment in Illegal Entries rebrands two small command buttons in the passport application into large-scale neon signs that prompt people to either "Read Instructions" or "Complete Form". Here, however, the neon effect and the illusion of the sign is animated.

61. Robert Morris, "Notes on Sculpture”, 231. 


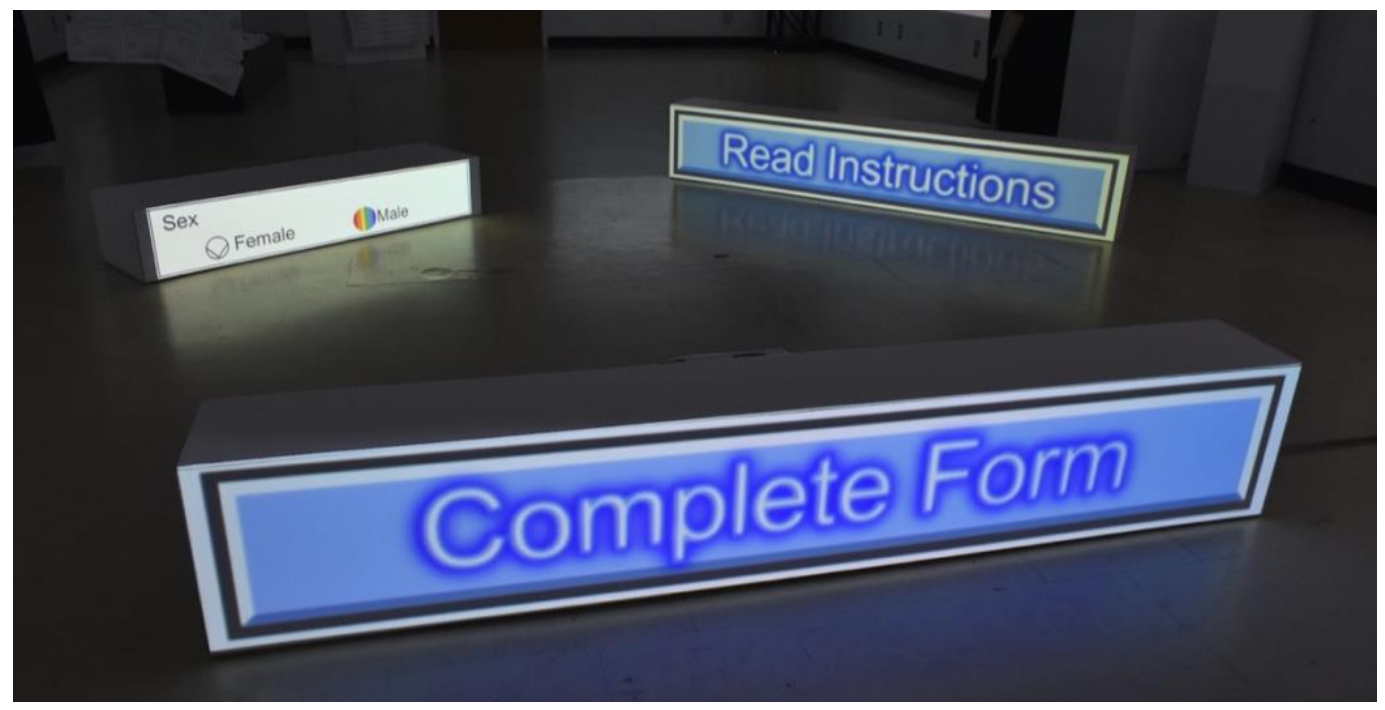

Figure 7. Tara Korkmaz, Illegal Entries, 2019.

The rationale behind this approach comes from the decision to use projection for all texts and icons that appear in the application. Projection creates immersive effects that awaken visceral experiences and, as a result, it works for creating the illusion that the audience is inside the application. Mixing the boundaries of architecture, text and image places the audiences inside the (space of) the application.

\subsection{Barbara Kruger}

In the course of our time, image and text have become active components in a system of fetishism and consumption. Images catch the eye by communicating a message motivated by the need for over-consumption and alienation. Text (and image) derail the realities of our era by enticing false empathy towards the subjects of socio-economic injustice or plainly by concealing this injustice. Especially strong is the idea that "capitalism highjacks affect to intensify profit"62

62. Massumi, Politics of Affect, 20. 
and that valorizing emotions through images is how the market fetishizes and commodifies agony.

Informed by critical theory, Kruger's art parodies cliché behaviour in capitalist society. Her imitation of catchy phrases makes the viewer evaluate their place in a society that appraises people by appraising their belongings.

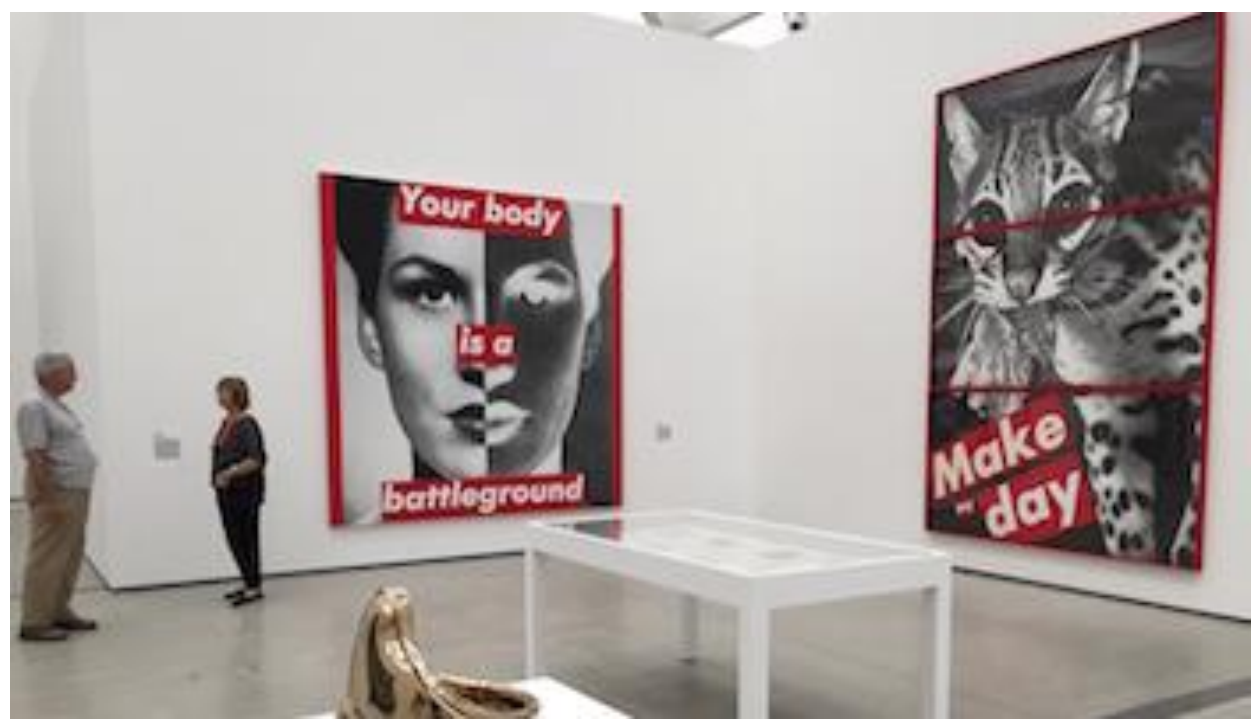

Figure 8. Barbara Kruger, Untitled (Your body is a battleground), 1989.

Text, image and architecture are essential components in Barbara Kruger's installations. She creates large-scale and immersive installations, utilizing elements that bring up provocative, critical conversations regarding social, cultural and political issues. Her room-wraps shout the words with gigantic and bold fonts. Kruger confronts needs and wants by using the same language that enslaves consumers, as they submit their bodies to the market's goods. Your Body is a Battleground (1989) calls for a battle with one's self, to free a body trapped by commercial slogans. ${ }^{63}$

63. Photographic silkscreen on vinyl, $(284.48 \times 284.48 \mathrm{~cm})$, shown in The Broad Museum. HoffPost.com. "New Museums: The Broad and the Whitney". http://images.huffingtonpost.com/2015-09-23-1443022725-7782577-KrugerBroad.JPG. 


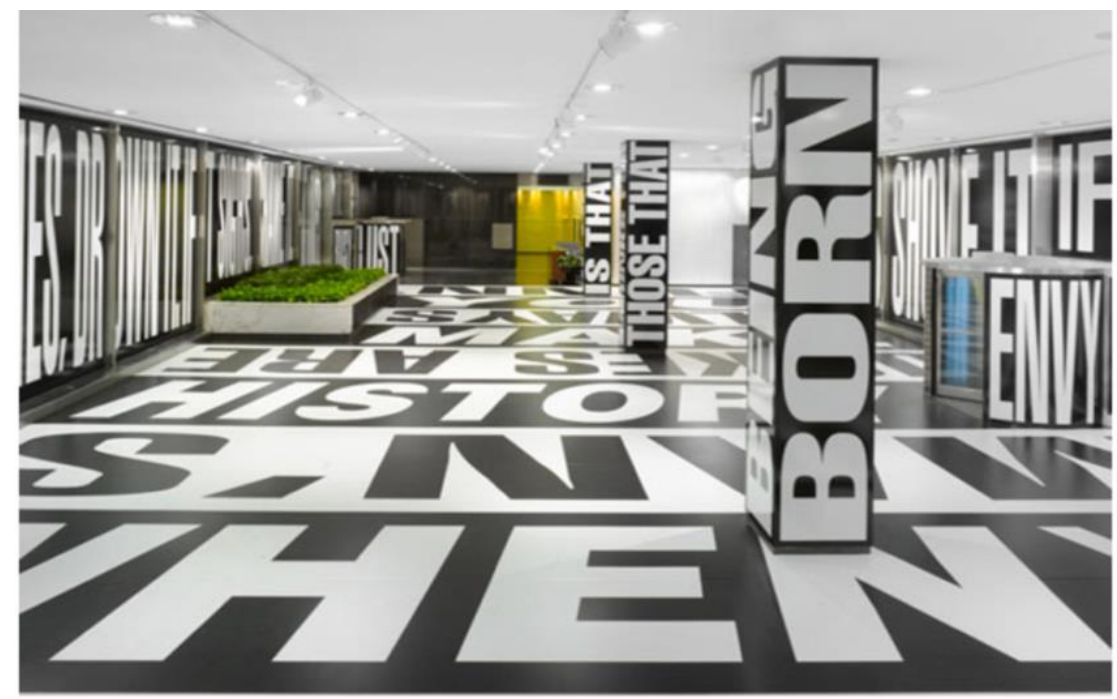

Figure 9. Barbara Kruger, Between Being Born and Dying, 2009.

Kruger's reconstruction of magazine texts and photographs, and her satirical commentary on societal norms and appropriated visuals also influenced this project. ${ }^{64}$ Her textual works and visual language speak to my approach to the idea of diversity. Diversity has turned into a slogan or a cliché, no longer reflecting its original meaning. People hear it and see it in public promotional videos and ads; they are inundated with this word to the point that they become numb and deaf to its meaning. And those (governments and institutions) who push for it, use the same devices to make the public aware of it as any other product for consumption — just another advertisement.

Magnifying the text and exposing it to an audience activates their encounters and their shared experience simultaneously. The flaw of institutional forms is in the reinforcement of social norms and the idea that sameness is better at bringing people together than acceptance of each other's differences. Every Canadian citizen who wants to travel abroad must complete this

64. Kruger's visual approach to text, https://www.designboom.com/art/barbara-krugerbetween-being-born-and-dying/. 
application. The experience of filling the blanks in the passport application is a shared experience of controlled conformity for all Canadians, born or naturalized, despite their differences. While standardization of the application system negates individuation, the commercialism of diversity suppresses the need for a more in-depth engagement with decisive differences that shape the society as a complex assemblage.

In the installation Illegal Entries, because of the change of scale, the viewers must distance themselves from the application fields to see them for what they are. Robert Morris's critical analysis of the use of space confirms that, "It is this necessary greater distance of the object in space from our bodies, in order that it be seen at all, that structures the non-personal or public mode." ${ }^{65}$

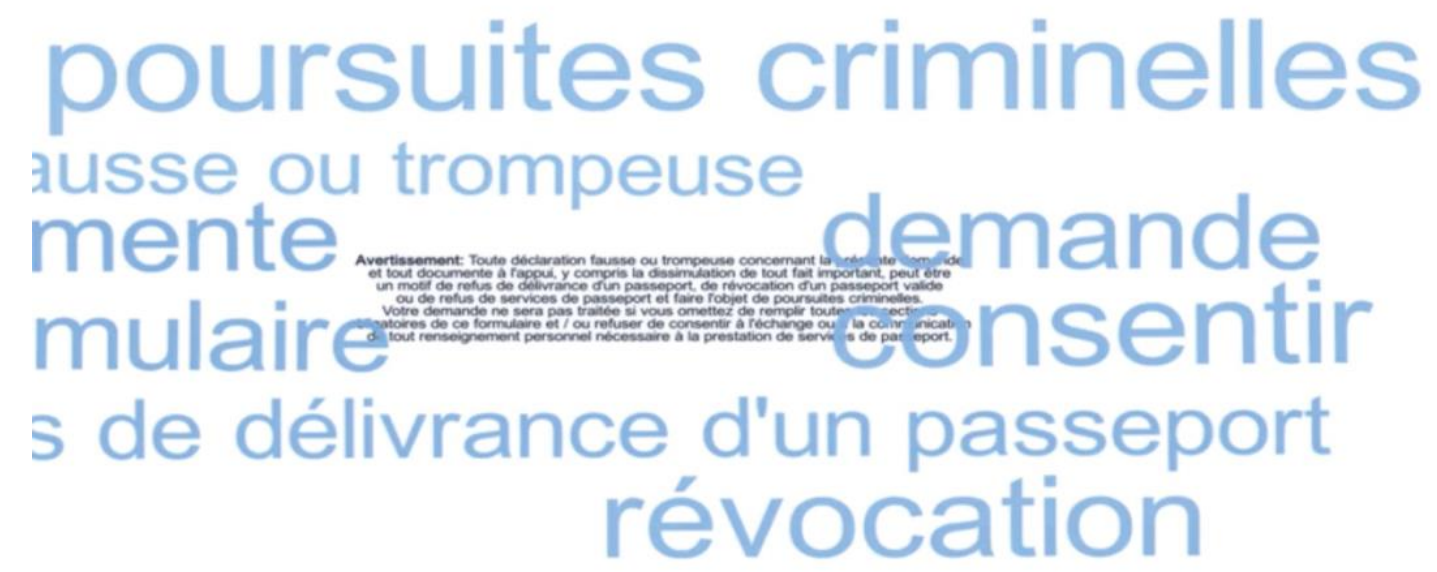

Figure 10. Tara Korkmaz, Screengrab of French text animation, Avertissement, 2018.

Appropriation and recontextualization of the "official" text in Illegal Entries reintroduces the body of the applicant with dignity. It counters the universality of the legal form, as it elaborates on and celebrates individuation and difference. The familiar text of the application

65. Robert Morris, "Notes on Sculpture" Art Forum, Vol. 4, no.6, February 1966, 231. 
form is animated to reveal its real purpose, that is, the erasure of the body that signifies difference and identity. On the other hand, the inserted information and the unexpected answers raise new questions. They illustrate a body scrutinized for its longing for a homeland. How far from reality is the place we call home?

\section{METHODOLOGY}

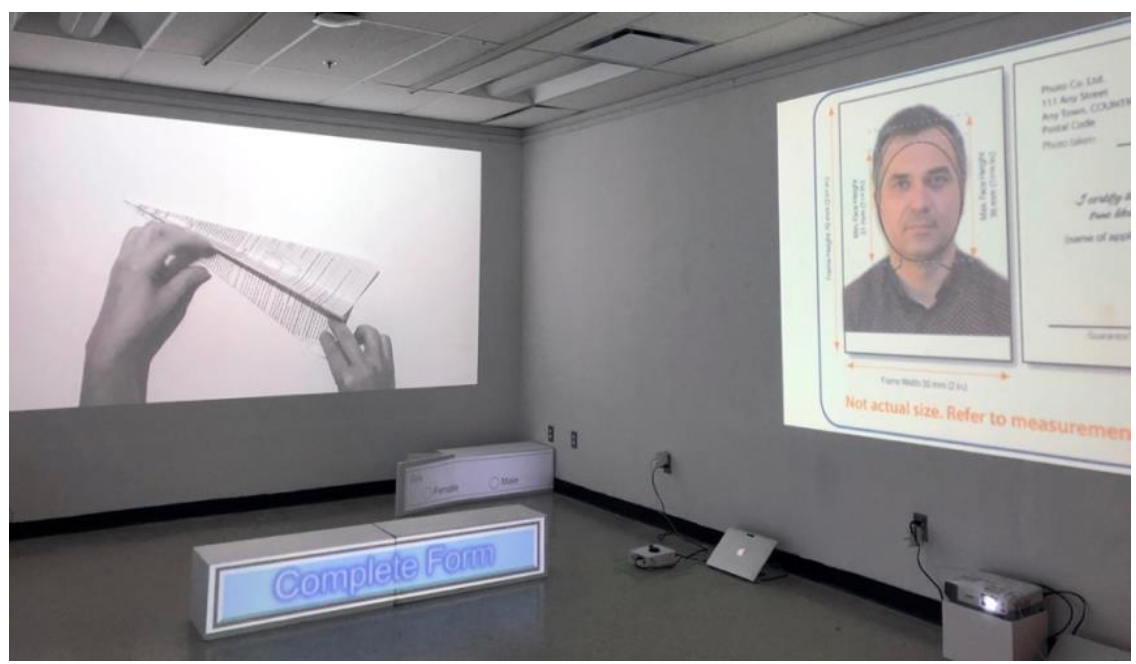

Figure 11.Tara Korkmaz, Illegal Entries, Test Install, 2018.

\subsection{The Rationale}

As previously stated, my journey through the Canadian citizenship process influenced a significant part of this research. I shared this story to reveal my skepticism about a more profound understanding of difference. I try to remove myself from the center of it to provide the audience with direct and controlled access to intimate experiences, which are more inclusive than exclusive. Parody, satire and tension make this approach possible while simultaneously honing the critical faculties of the audience.

Decoding the concept of difference, as a driving force shaping modern society, allows us to tease out its exploited version, which capitalism calls diversity. To this point, a parodic 
approach, as explained by Linda Hutcheon in "The Politics of Postmodernism: Parody and History," ${ }^{66}$ would draw the most effective connection between the real and imagined difference. Hutcheon redefined parody as "repetition with critical distance that allows ironic signaling of difference at the very heart of similarity." ${ }^{67}$ She explains, "Parody seems to offer a perspective on the present and the past which allows an artist (To) speak a discourse from (WITHIN) it, but without being totally recuperated by it." ${ }^{68}$ Moreover, Hutcheon views parody as a popular and effective strategy amongst black, feminist, queer and other marginalized artists who try to come to terms with and respond creatively to the hegemony of dominant powers and critics. She argues, "Parody appears to have become, for this reason, the mode for marginalized, or of those who are fighting marginalization by a dominant ideology. ${ }^{\circ 69}$ In this way postmodern parody is less about ridiculing something and more about taking the familiar out of its context and reusing it as critique, in hope for change. She states, "for both artists and their audiences, parody sets up a dialectical relation between identification and distance." ${ }^{70}$ In Illegal Entries, utilizing parody allowed me to simultaneously connect with and detach myself from my work, and create pulses of interest that set the mood for this installation.

Another strategy is more specific to the individual elements and objects in my critique. Texts and images filter through a variety of media in order to disclose and challenge them as

66. Hutcheon, Linda. "The Politics of Postmodernism: Parody and History." Cultural Critique no. 5 (1986): 179-207. P. 206.

67. Hutcheon, Politics of Postmodernism, 206.

68. Ibid., 206.

69. Ibid., 208.

70. Ibid., 206. 
paradigms of description and representation. As a result, words transform in size and shape, images shift between motion and stillness, and poetry responds to cold facts.

The purpose of poetry is to reveal different use of the same words, or to invoke emotive reaction and critical responses. Poetry is ingrained in cultures of resistance. In my installation, the aesthetics and rhythms of poetry are a parodic face-off to the banality of the institutional structure of the texts.

\subsection{Timeline}

From the early stages of my migration journey, I became aware of difficulties surrounding the freedom of movement for people outside of the Western hemisphere. It is no secret that non-Western bodies are under stricter surveillance systems. Their place of birth follows them wherever they go in global currents of exclusion and inclusion. It positions them in a type of artificial difference, constructed through political agendas. For the most of my journey, I was gazed at as criminal when crossing borders. Yet, I was one without any criminal records.

Palestinian poet Mahmud Darwish writes, "I have learned and dismantled all the words to draw from them a single word: Home." 71 However, I learned that I needed a passport to take me there. In fact, the Canadian passport application indicates: "A Canadian passport is the only reliable and universally accepted travel and identification document for Canadians who travel abroad." ${ }^{\prime 2}$ The passport also brings people back home.

71. Mahmud Darwish and Munir Unfortunately, It Was Paradise Selected Poems. Berkeley: Univ. of California Press, 2013.

72. Page 4 of Canadian passport application. https://www.canada.ca/content/dam/ircc/migration/ircc/english/passport/forms/pdf/pptc153.pdf. 
The road to obtaining a Canadian passport stretched very long for me. Longer than walking the ten thousand kilometer distance between my new and old homeland on foot. I decided to dismantle all the words that compromise the meaning of home and identity through law and order. Here, I want to ask: Who was I during the time I spent on that road? The person who left Iran? The person who was arriving in Canada? Or Both? Or Neither?

In the year 2000, months before applying for a Canadian Passport and as I was waiting every day to hear the news about becoming a Canadian citizen, I printed my passport application and doodled emotional short-sentence answers on it. Many thoughts of providing different responses to the questions asked on the passport application emerged from my objection to being reduced to and registered as a set of entries on a form. However, I ended up completing the application flawlessly with the requested information.

Finally, in the past two years, I found the determination, and the tools to revisit those times and to dedicate my research to an interrogation of how such application forms work. As a result, this project is about being able to finally document the actual answers that I believe needed to be registered and archived in response to the inquiries on the form, while taking into account that the short answers were not enough; they did not do justice to the recognition of the subjects in question. The gestation of these thoughts and texts follows in the paragraphs below.

I revisited my thoughts from the past in Fall of 2017. In an extended narrative that I was preparing for the Media Writing course, longer answers then became revelatory entries that did not fit on one page. I copied each question field and pasted it on a new page, to create space for what I thought was the right response. After completing each new answer, I copied and pasted the next question followed by the creation of the subsequent replies. I kept the fonts and 
formatting from the application for the questions and warnings, and cropped and copied all the sections of the form. Then, I wrote my answers that had now turned into opinions and statements - in another font, distinguishably different from each of the separate fields.

Through this process, in December 2017 an extended narrative came to life. My desire for documenting the truth sparked the idea of resisting the oversimplifications necessary to apply for and receive a Canadian passport.

The different texts reflected the tension between the actual person and the system of governance. The narrative worked both as a story and as the representation of a body tangled in textual trickery. Banal and shallow questions, which operated as truth-eaters, simply choked by my refusal to give them the known, the calculated and the expected.

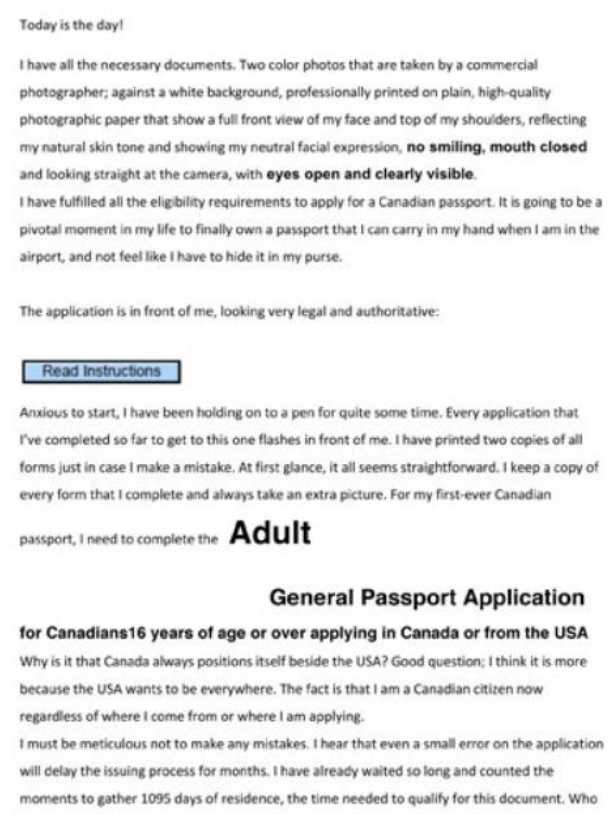

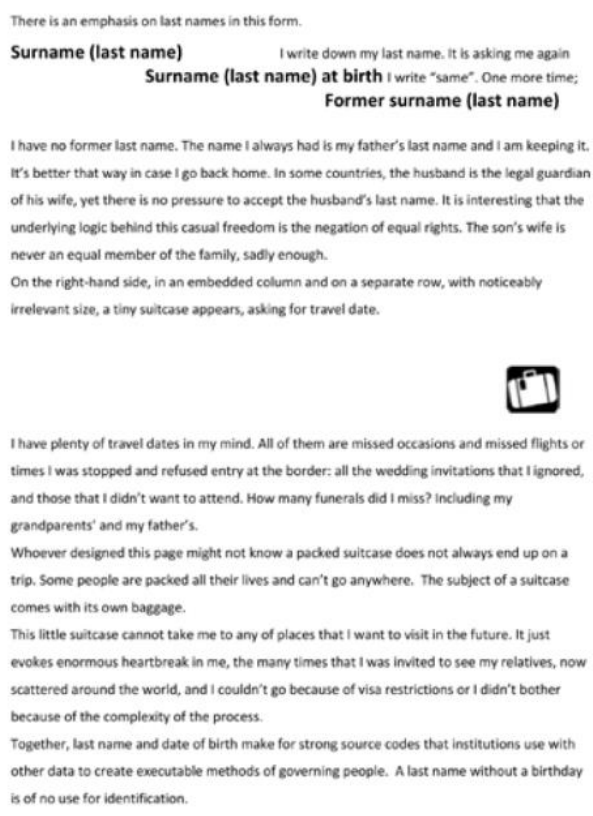

Figure 12. Tara Korkmaz, pages from Extended Narrative, 2017.

While conducting my research I explored various methods of documentary practice that intervene in existing texts or fonts. I also considered including poetry in my project, as a form of 
writing that disrupts and counters the legal document because of its ostensive power. By March 2018, I knew that my thesis work would focus entirely on the application. I narrowed down the sources for outlining my research paper and the visual inspirations for my installation.

However, while working on the extended narrative, written responses for each question would awaken associations with different fragments of time. It gave me the idea of a more indepth deconstruction of the form. For example, the questions about the "Date of birth" and "Place of birth" took me to a time far in the past, whereas the answer to the "Natural eye color" inquiry still lives in the present. In comparison, the question about the "Anticipated date of travel" is about the future. Accordingly, the segments related to each field reflect different dimensions of time. Through these considerations, by the end of spring 2018, I realized the need to expand my ideas beyond writing. Time and space became dynamic factors of the project.

Through the process of editing and with each revision, vivid visuals of undesired answers ruptured the application form, triggering a multi-dimensional journey. Thus, the decision to move the project into a digital sphere was a natural evolution: this is the space of forms and applications these days. Now, the preferred way to fill out the application form is in cyberspace, where the intangible nature of these applications makes them further detached from the applicants. Paradoxically, the document expands its territory as it enforces boundaries and sets limits.

Both text and photographs have departed from the paper a long time ago, which gave my work permission to cross those borders. For example, I refused to remember the place of my birth, which was reduced to its constructed boundaries. I know a question about my birthplace is to put me on the map, via a term which is more political than geographical or environmental. My response emphasizes that I was born in my mother's lap, which is the one crucial fact that 
individuates me. What if someone was born on an airplane? As a result, in the installation Illegal Entries, my response to the "Place of birth" appears in a video montage of archival childhood photographs that dissolve over an elusive sandy landscape ${ }^{73}$ For a migrant's place of birth is a saltating dune whose fluid fragments twirl in memory.

Darwish asks: "Where can I free myself of the homeland in my body?"74 For years, I considered visions of "homeland (trapped) in the body," a natural outcome of migration. I continue to think about bodies confined in their homeland, those who cannot travel anywhere, people without passports. I often externalize these intense feelings, since I have been carrying my homeland in my body as long as I remember. My project relies on such intensities to evoke emotion. "Intensity," states Brian Massumi, "would seem to be associated with nonlinear processes: Intensity is qualifiable as an emotional state, and that state is static-temporal and narrative noise. It is a state of suspense, potentially of disruption." 75

Those who experience the anxiety and stress of completing a legal document or an application form understand tension. The space constraint, the banality of the required information, and the hidden insensibilities are all in a convulsion within individual's body. Therefore, tension is interlaced into the project's methodology, and branches out to all of its elements. My strategy, both in this paper and in the installation, has been to provoke more

\section{See Figure 20, Appendix B.}

74. Mahmoud Darwish, Unfortunately, It Was Paradise: Selected Poems.

75. Brian Massumi, “The Autonomy of Affect." Cultural Critique, no. 31 (1995): 83-109. doi:10.2307/1354446. Massumi also explains "An emotion is a subjective content, the sociolinguistic fixing of the quality of an experience which is from that point onward defined as personal." The static-temporal is in relation to space-time and individual experience as memory. 
questions through treatment of the answers. In "Appendix A" I have included detailed diagrams to show such process.

During the summer of 2018, I worked on separating each field in the application into digitized files, utilizing animation, audio and digital effects. The answer to each field's question was considered and executed based on the individual concepts related to that field and also determined by the medium used. For example, the answers to the "Name" question became a series of poems I wrote in response to people's reactions when hearing my unfamiliar name and to the stories that I heard from other people about their names.

The response to the "Sex" question field was a reaction against a lack of understanding and acceptance since the application falls short of recognizing sex and gender in Canadian society beyond the ideology of binary structures. The standard form for the Canadian passport only allows for a limited choice of sex. As a result, the response to the "Sex" field in my installation is an animation of the rainbow colors, appearing and vanishing over male and female signs taken from cave drawings. ${ }^{76}$ Consequently, the investigation of the applicant's sex awaken concerns about gender roles and differences instead of reaffirming binary norms of sex and gender. Is the female/male choice appropriate for the reality of gender in Canadian society? Additional images of wordplay and transformation of fields is included in Appendix B.

Another consideration for challenging the application form was through countering its appearance. The text that hides the authoritative and penalizing nature of the application form in its fine print must be exposed. Commands such as "Read Instructions" and "Complete Form" become large and flickering neon signs. There is tension between rapid visual movements and

76. See Figure 13, Appendix. The chart illustrates how this approach prompts the intended results. 
the silence that surrounds them as they flash endlessly, similar to muted lightning. These commands are small and skillfully obscured in the corners of the application. However, as largescale signs they reveal their disciplinary purpose.

As a result of my discovery that Jenny Holzer used quotes from Mahmoud Darvish in her installation, I identified more parallels with her practice. She has created many works through intervening in official government documents, such as entering her handwritten notes in classified government briefings, rewriting the strategic war maps from the Iraq war, and even using autopsy reports of detainees killed while in U.S. custody in Iraq and Afghanistan. Holzer's political concerns guide her methods for illumination, augmentation and the use of documents, in addition to manipulation of light, scale, and text. Similarly, in my installation, I aimed to carry the mundane appearance of the application forward, while augmenting and rearranging all of its pieces with enough exaggeration to create a spatial illusion. This transformation brought the audience inside the application (a large room filled with question and answers). It also underlines the importance, and emphasizes the weight, of each given response. The fields seem to ask simple questions, but the replies are far from one word or two numbers. They are images, memories, poems, sounds and beats that function as different parts of the assemblage ${ }^{77}$ known as the body.

I thought of ways to imbed the complexity of individuation within the answers that I provided for the application form. Holzer's light projection on exterior walls of the New York Public Library included “I Belong There” from Darwish's poem Unfortunately It Was Paradise. Holzer works with both poetry and documents. I chose to write poetry in the document.

77. Gilles Deleuze and Felix Guattari, A Thousand Plateaus: Capitalism and Schizophrenia. Bloomsbury, 2017. 
The ESL Poems ${ }^{78}$, as I call them, emerged during the years that I was trying to learn English. They became the voice of my silence towards many things that I had to do to fit in. My poems have intentionally fragile compositions. They tell tirelessly of the never-ending search for a homeland, in a language that has replaced my mother tongue. So, I rephrase Mahmud's question as "Who is the owner of the language of this land?" The one "Who loves it more?", or the one "Who writes it better?" Regardless of the answer, I continue to write poetry.

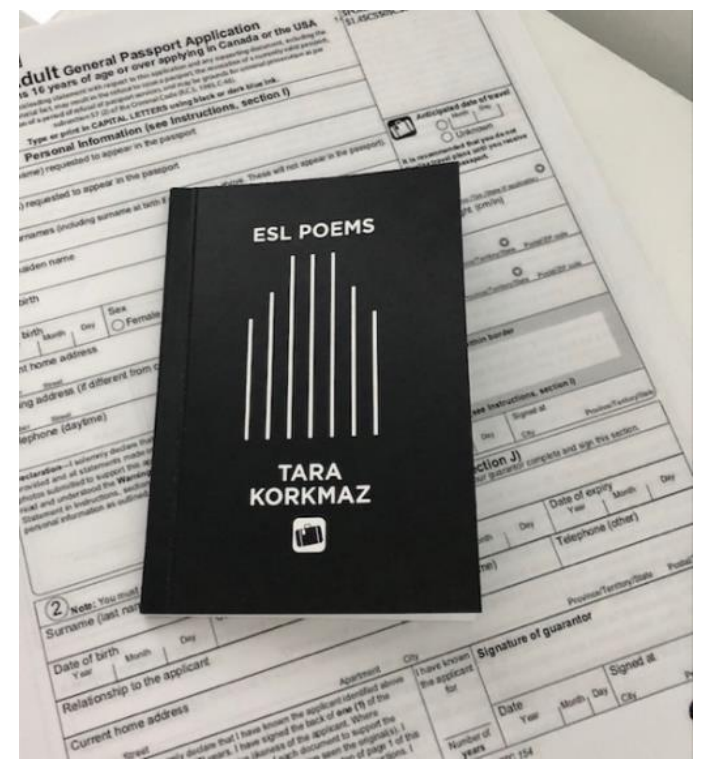

Figure 13. Tara Korkmaz, ESL Poems, 2019.

Aside from the texts in the Canadian passport application, the applicants must submit unaltered passport photographs as visual identification that certify their "true likeness." The photo instruction in the Canadian passport form motivated me to re-enact and document the transition from a live person to a still image. The idea to perform the photograph from the moment of sitting for the portrait to the moment of becoming a photograph was rendered into several short clips portraying the several different faces of people who identify as Canadian. The

78. Here, I refer to English as a Second Language, a language curriculum designed in an English-speaking nation for newcomers whose native language is not English. 
concept of difference fades in Canadian version of diversity, as the live moving faces and their unique expressions freeze in the last frame to comply with the photo descriptions.

My work on the passport photos started in the fall of 2018. I shot various videos of people who were interested in my project. The participants were all adult, Canadian citizens reenacting their experience of sitting for a passport photograph. These short videos that transition into still photographs, highlight the process of becoming a Canadian based on sameness. They bring attention to the fact that to be considered for Canadian citizenship one must be simplified into data and "act" according to a particular image. The live persons prepping themselves for their passport photo freeze in a flash, to document an instance of their existence that reveals nothing about them but their appearance at that moment. Through a parodic approach to the passport portrait, this re-enactment points to multiculturalism as an "Act".

As mentioned earlier, Sekula draws attention to Bertillon's description of criminal body as a "body that expresses nothing." He explains, "No characterological secrets were hidden beneath the surface of this body. Rather, the surface and the skeleton were indices of a more strictly material sort." ${ }^{79}$ Sekula also emphasizes that "For Bertillon, the mastery of the criminal body necessitated a massive campaign of inscription, a transformation of the body's signs into the text, a text that pared verbal description down to a denotative shorthand, which was then linked to a numerical series." $" 80$

A request for the textual description of the body is the modern-day version of Bertillon's "portrai-Parlê". Over one century later, bio-positivist quantification of the body has only

79. Alan Sekula, The Body and the Archive, 30.

80. Sekula, 33. 
intensified, and continues in the process of applying for a passport. The passport application, however, goes further than that and warns the applicant that noncompliance with the

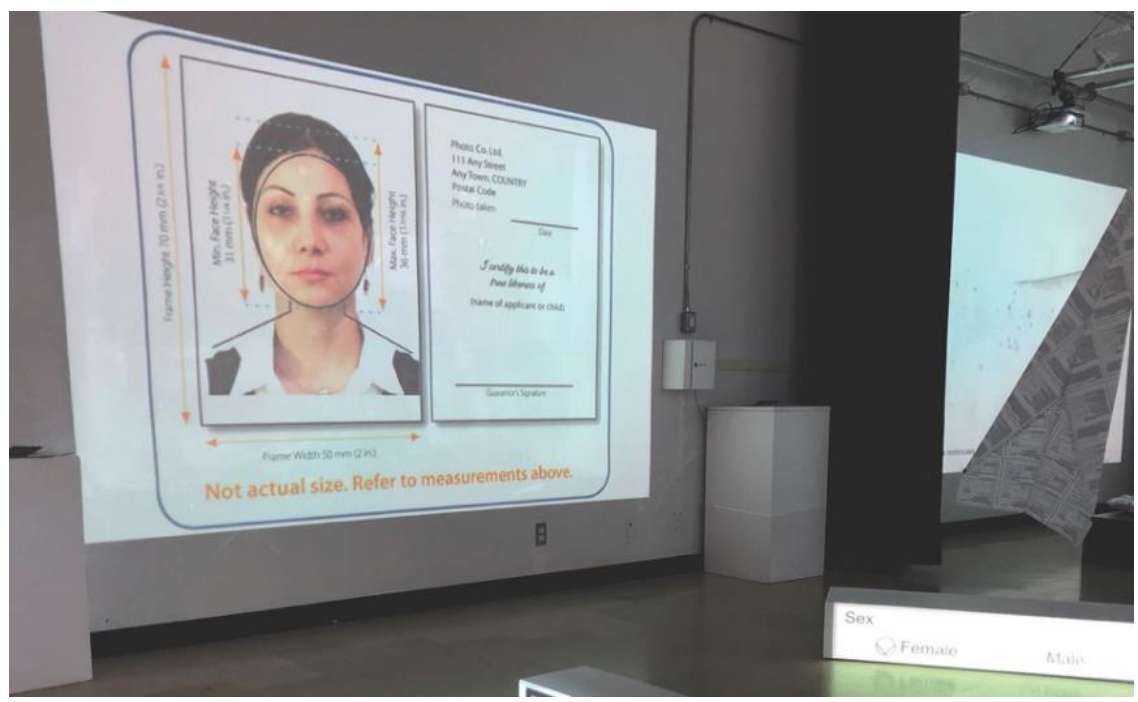

Figure 14. Tara Korkmaz Installation, Illegal Entries, June 2019.

criminalization of the body will result in criminal prosecutions. The audio that accompanies these clips is a digitized voice that reads the "Canadian Photo Instructions" stated in the application form. The artificial sounds aim to recreate the detachment and distance that resides in the legal and governmental apparatus. On the other hand, organic sounds such as speech, songs or environmental noise act to evoke emotion and affect. It all works to maintain tension between different types of texts, between text and image, moving image and still photograph, image and sound and the tensions between various types of sounds. The definitive work on audio did not start until December of 2018, and some of the re-recording and editing extended into May 2019.

The use of metaphor in the work determined the focus on certain sounds. "Metaphors almost always operate by pairing more-concrete concepts with less-concrete concepts, thus making the abstract concept accessible to thought." ${ }^{81}$ As explained earlier, the themes of

81. Hans Bork, "Wind, Wave, and Generative Metaphor in Greek" (2011). P.9. All Theses and Dissertations (ETDs). 463. http://openscholarship.wustl.edu/etd/463. 
individuation, change and migration are the core concerns of my project. As such, the speech aims to reflect the artist's individuated voice. Birds' migration and airplane engines reflect global movement of bodies, and wind alludes to change as a carrier of things. ${ }^{82}$ These sounds and metaphors augment the meaning of abstract concepts in the Canadian passport application form.

\section{CONCLUSION}

By transforming a document that registers Canadian identity into a documentary, Illegal Entries highlights the need for a more in-depth understanding of diversity in Canada. Artistic intervention, deconstruction and manipulation of this document as an object of power legitimization shows that the redaction and similitude imbedded in this document is the prevalent method of this legitimization, not acceptance and appreciation of individuation and difference.

Therefore, the critique of the commercialization of diversity in Canada is connected to the need for understanding difference in a multicultural society. However, a consumerist approach encouraged by the capitalist structures and archaic systems of control benefit from a limited grasp of diversity.

I explained the problems with traditional treatment of text and image in documentary portrayal of social complexities. My research takes notice of artistic practices that employ these tools in innovative ways. The installation Illegal Entries undertakes various methods and media that activate text, image and sound without invading personal and cultural spaces. In that sense my project is interested in affects rather than emotions. It is interested in assemblages of

82. Hans Bork, "Wind, Wave, and Generative Metaphor in Greek" (2011), 9. 
difference that form Canadian society, not the reframing of diversity as slogan and diversity as facade.

My work urges viewers and readers to look deeper into each-others' differences, and search for a better definition of diversity in Canada, to view difference as a positive force that makes everything in the universe move forward. As bodies perform through their different organs, society too functions through heterogeneity. Forces that colonized different bodies through systemic erasure will sell many versions of diversity in the hope of maintaining their hegemony. Appreciation of true difference strengthens the power of people.

Wordcount: 10588 
Appendix A

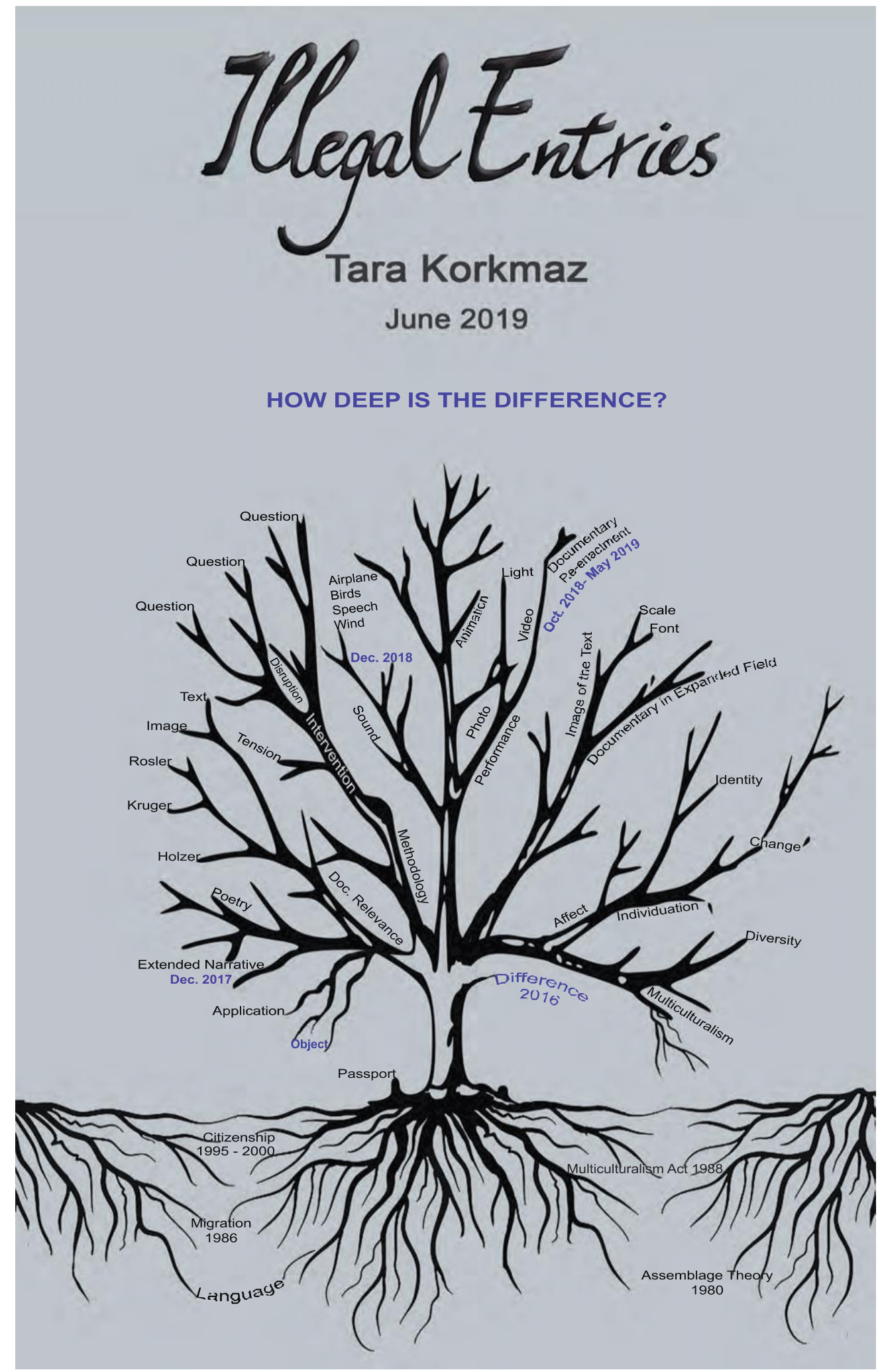

Figure 15. Tara Korkmaz, Timeline/ Methodology, Vinyl, 117” X 36”, 2017- 2019. 


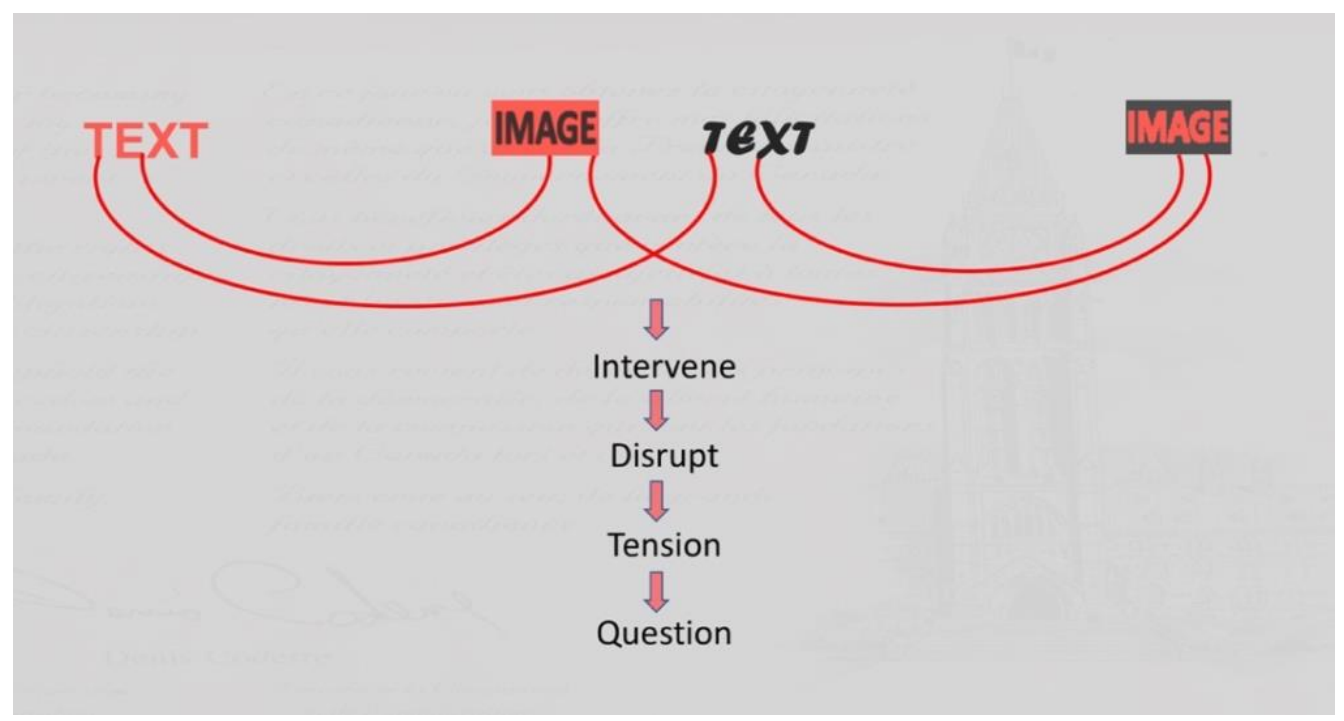

Figure 16. Tara Korkmaz, Methodology and Process 2017-2019.

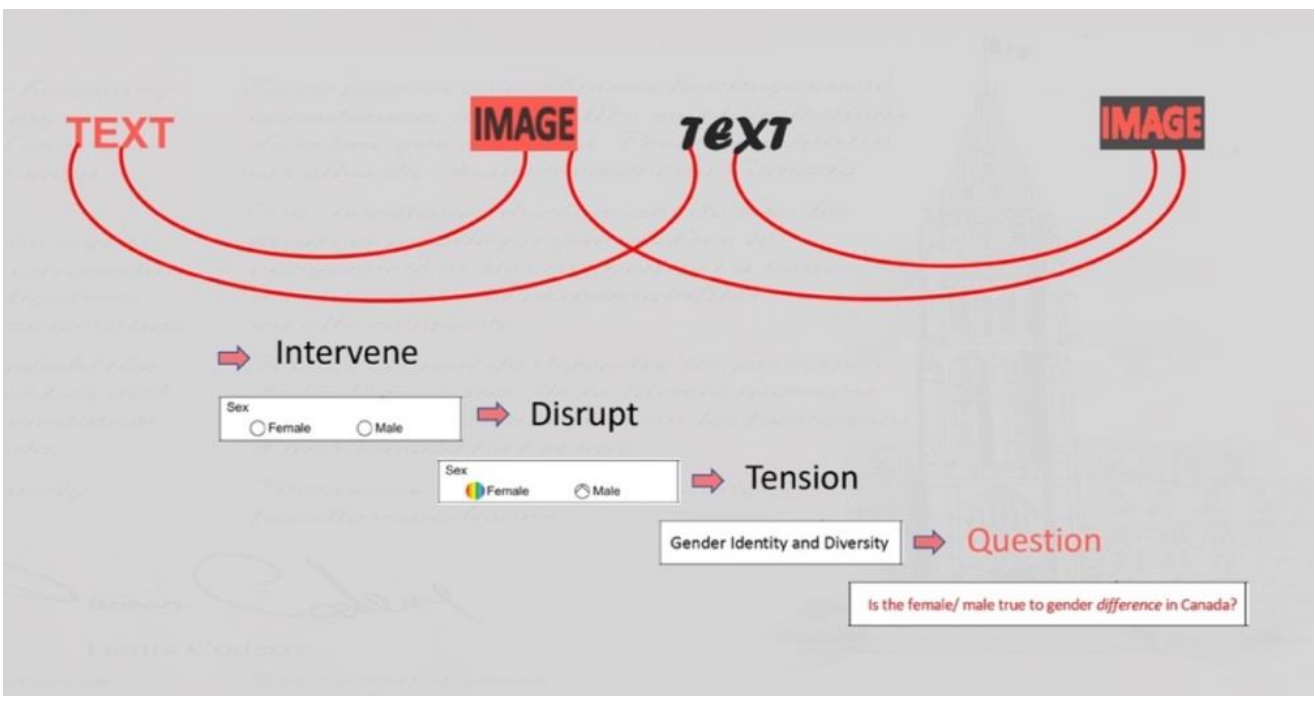

Figure 17. Tara Korkmaz, Questioning the Questions, 2017-2019. 


\section{Appendix B}

Wordplay of the Passport Application Fields:

Figure 18. Names:

I Changed My Name. It Was Too Long.

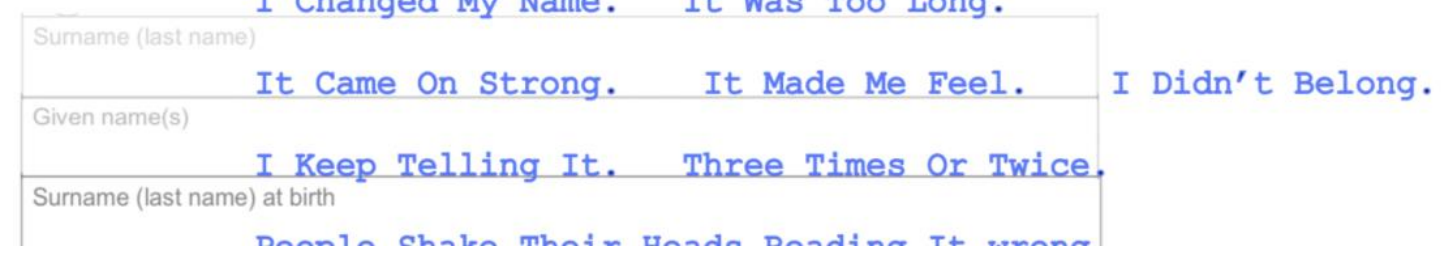

Figure 19. Place of Birth:

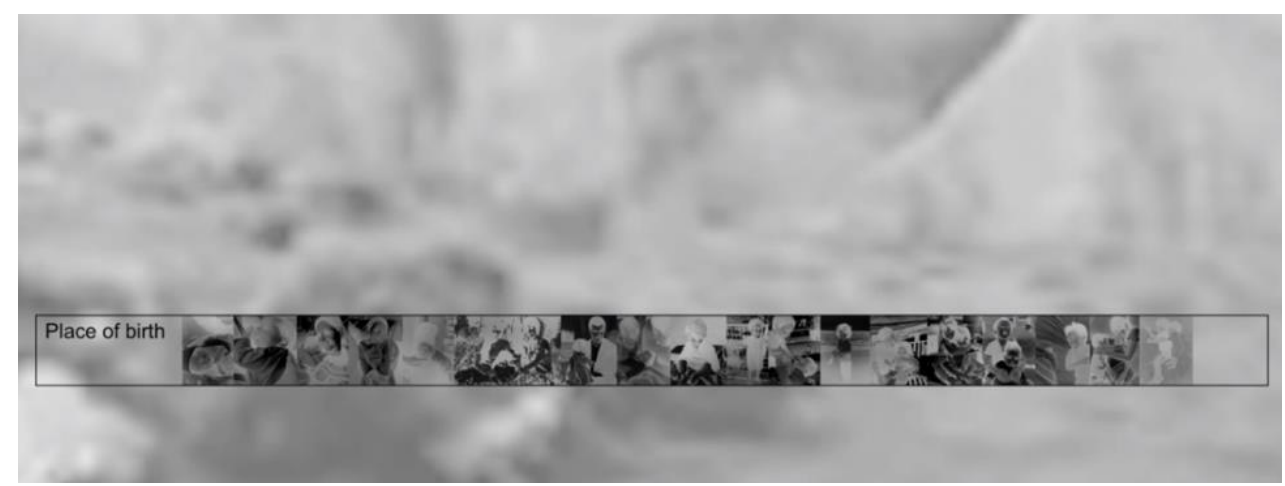

Figure 20. Date of Travel:

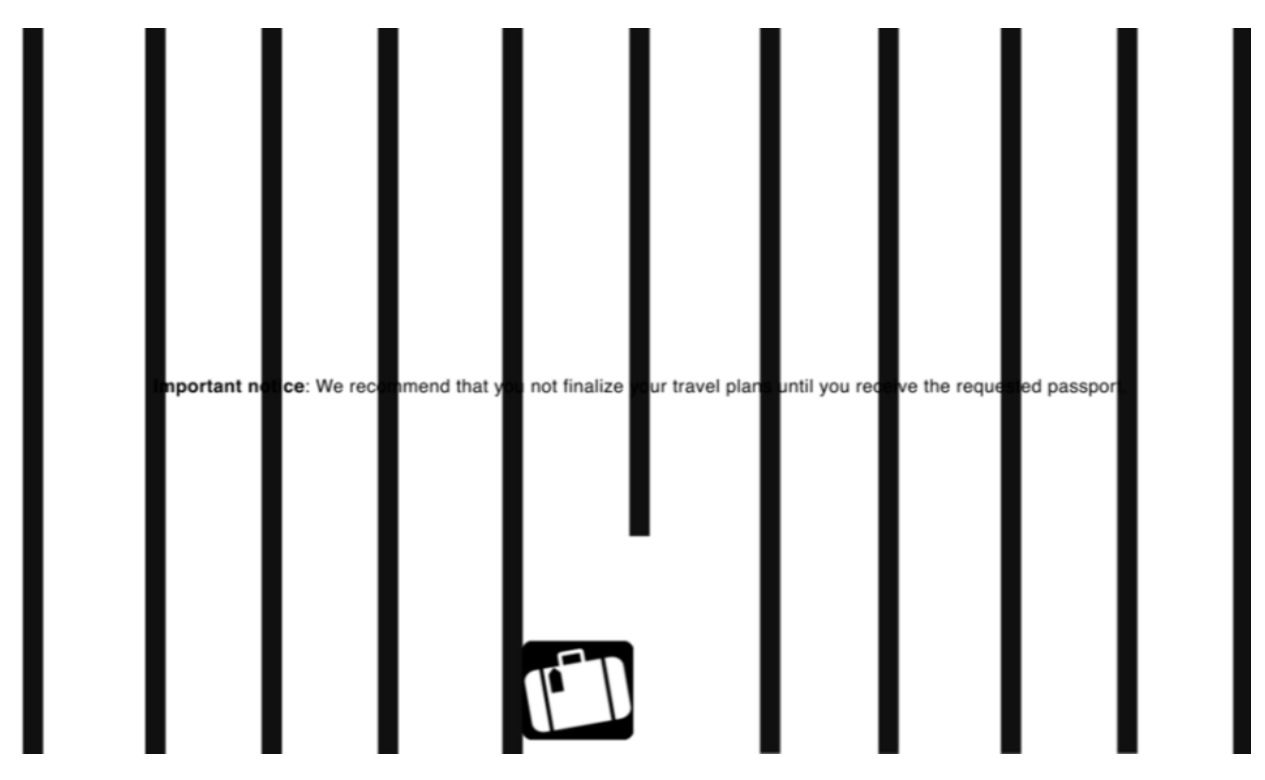


Figure 21. Sex:

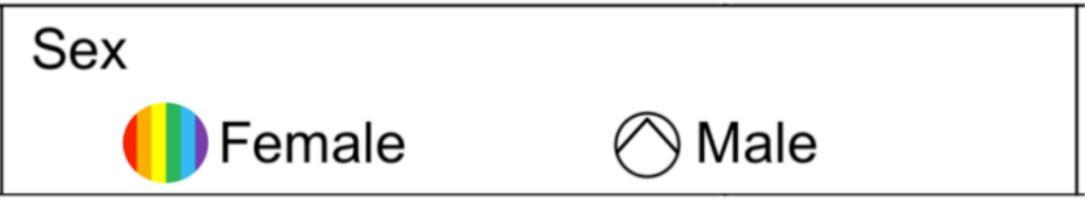

Figure 22. Natural Eye Color:

\section{Natural eye colour}

Figure 23. Height:

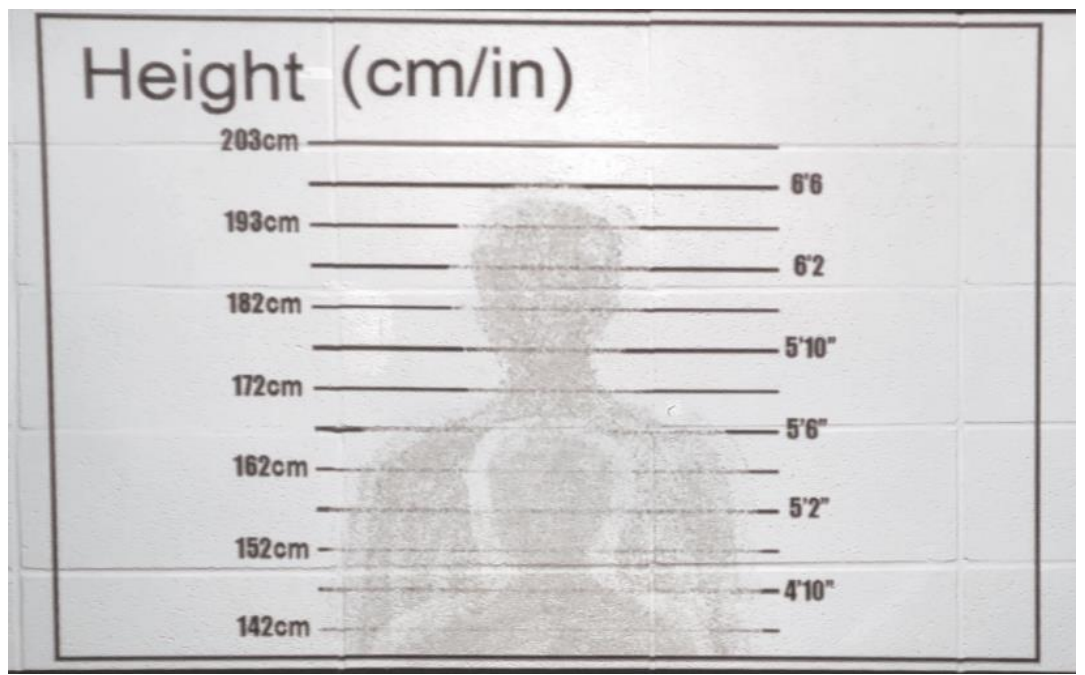

Figure 24. Current Home Address:

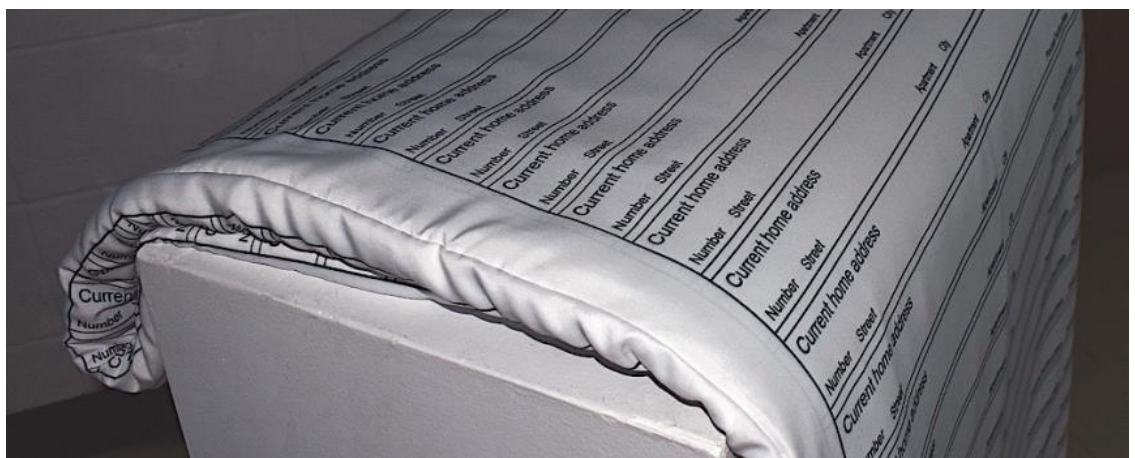


Figure 25. Signature:

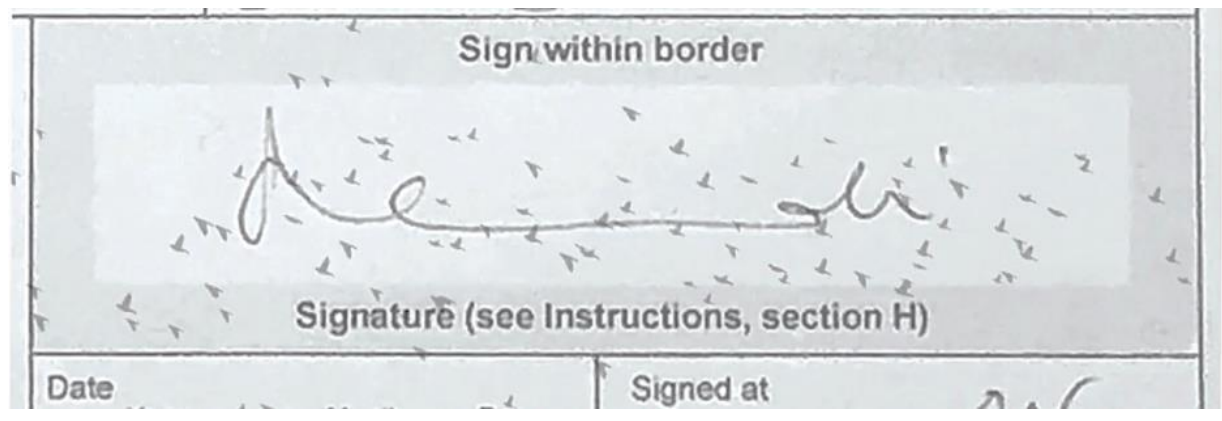




\section{Appendix C}

Signature Field Text

Menagerie, written by Tara Korkmaz

Across many cultures, birds represent freedom.

Not because they can fly. Nowadays everyone can fly.

It is because they have the freedom to fly without restrictions.

When life gets harder, birds can fly away and go to better places. Some relocate close by, and some migrate very far.

One might find those resilient birds that stay behind admirable.

Fighting and resisting are heroic, but only possible if birds can find a way to warm up their feathers, or how else would they survive?

Most likely, domesticity and captivity are some of those options.

Migration is an instinct, a natural act of survival.

Amongst birds, it is common to fly to places with more favorable conditions, to breed and raise their families.

In the springtime when flocks of birds arrive, they bring hope for new beginnings.

Their migration is viewed with beauty and wonder.

When birds migrate in large clusters, everyone cheers for their unity, no one feels threatened by their mass arrival.

Birds have different nationalities, like Canada Goose, American Eagle or Spanish Sparrow. They don't need permission to cross borders. They couldn't care less for international boundaries.

And as they settle in different countries, they do not lose their identities. American Eagles remain American, regardless of where they stay.

Migration is a natural survival Instinct for those who arrive at a moment in their lives and imagine themselves in a different place, one that allows them to continue to exist.

And, it is all about that.

Everyone just wants to exist.

Everyone just wants to be free to exist. 


\section{Ménagerie}

\section{French Translation by Dr. Bruno Lessard}

Dans de nombreuses cultures, les oiseaux représentent la liberté.

Non pas parce qu'ils peuvent voler. De nos jours, tout le monde peut voler.

C'est parce qu'ils ont la liberté de voler sans contrainte.

Quand la vie devient plus ardue, les oiseaux peuvent s'envoler pour d'autres endroits plus favorables. Certains se relocalisent tout près et d'autres migrent très loin.

On pourrait penser que ces oiseaux résilients qui restent sur place sont admirables.

Se battre et résister sont des actions héroïques, mais c'est seulement possible si les oiseaux peuvent réchauffer leurs plumes, sinon comment feraient-ils pour survivre?

Généralement, la domesticité et la captivité sont quelques-unes de ces options.

La migration est un instinct, un acte naturel de survie.

Pour les oiseaux, il est commun de s'envoler vers des endroits aux conditions plus clémentes pour s'accoupler et élever leur famille.

Au printemps, lorsqu'une volée d'oiseaux fait son arrivée, elle emporte avec elle un espoir de renouveau.

Sa migration est perçue avec beauté et émerveillement.

Quand les oiseaux migrent en grands groupes, on se réjouit de leur unité; personne ne se sent menacé par leur arrivée collective.

Les oiseaux possèdent différentes nationalités, telles que la bernache du Canada, l'aigle d'Amérique ou le moineau espagnol. Ils n'ont pas besoin de permission pour traverser les frontières. Ils n'ont que faire des frontières internationales.

Au fur et à mesure qu'ils s'établissent dans différents pays, leurs identités ne sont pas déracinées. Les aigles d'Amérique demeurent les aigles d'Amérique, peu importe où ils se trouvent.

La migration est un instinct de survie chez ceux qui arrivent à un moment dans leur vie et s'imaginent dans un endroit différent qui leur permettra de continuer d'exister. Et c'est tout ce qui compte.

Tout le monde veut juste exister.

Tout le monde veut juste être libre d'exister. 
Bibliography

Barthes, Roland. The Pleasure of the Text. Trans. Robert Miller. New York: Hill and Wang, 1975.

Bennett, Colin J. and David Lyon. Playing the Identity Card: Surveillance, Security and Identification in Global Perspective. London; New York: Routledge, 2008.

Berger, John and Jean Mohr. Another Way of Telling Pantheon, New York: Pantheon Books, 1982.

Bourriaud, Nicolas, Caroline Schneider, and Jeanine Herman. Postproduction: Culture as Screenplay: How Art Reprograms the World. The Use of Objects. ed. New York: Lukas \& Sternberg, 2002.

DeLanda, Manuel. A new philosophy of society: Assemblage theory and social Complexity. London: Bloomsbury. A\&C Black, 2006.

Deleuze, Gilles and Paul Patton. Difference and Repetition. London: Continuum, 2004.

Deleuze, Gilles, Félix Guattari, and Brian Massumi. A Thousand Plateaus: Capitalism and Schizophrenia, Minneapolis: University of Minnesota Press, 1987.

Edwards, Steve. Martha Rosler: The Bowery in Two Inadequate Descriptive Systems. London. Afterall, 2012.

Gramsci, Antonio, Quintin Hoare, and Geoffrey Nowell-Smith. Selections from the Prison Notebooks of Antonio Gramsci. 1st ed. New York: International Publishers, 1971.

Harper, Douglas. "Talking about Pictures: A Case for Photo Elicitation." Visual Studies 17, no. 1 (2002): 13-26.

Krauss, Rosalind. "Sculpture in the Expanded Field." October 8 (1979): 31-44. doi:10.2307/778224.

Kruger, Barbara. 1993. Remote Control: Power, Cultures, and the World of Appearances. Cambridge, Mass: The MIT Press, 1993. eBook Collection (EBSCOhost), EBSCOhost (accessed March 02, 2018).

Lee, Eliza Wing-yee. "Political Science, Public Administration, and the Rise of the American Administrative State." Public Administration Review 55, no. 6 (1995): 543-44. doi:10.2307/3110345.

Mackey, Eva. The House of Difference: Cultural Politics and National Identity in Canada. Vol. 23. Toronto. University of Toronto Press, 2002. 
Malek, Amy. "'if You'Re Going to Educate 'Em, You'Ve Got to Entertain 'Em Too': An Examination of Representation and Ethnography in Grass and People of the Wind." Iranian Studies: Journal of the International Society for Iranian Studies 44, no. 3 (2011): 313-325.

Masny, Diana and Monica Waterhouse. "Capitalism, Immigration, Language and Literacy: Mapping a Politicized Reading of a Policy Assemblage." Policy Futures in Education 14, no. 7 (2016): 1005-1019.

Marshall, Julia. "Image as Insight: Visual Images in Practice-Based Research." Studies in Art Education 49, no. 1 (2007): 23-41. http://www.jstor.org/stable/25475852.

Massumi, Brian. "The Autonomy of Affect." Cultural Critique, no. 31 (1995): 83-109. doi:10.2307/1354446.

Nichols, Bill. "What Types of Documentary Are There?" Introduction to Documentary. Bloomington, Ind: Indiana University Press, 2001.

Nichols, Bill. "Documentary Reenactment and the Fantasmatic Subject." Critical Inquiry, 2008. 35 (Autumn), 72-89.

Robertson, Craig. The Passport in America: The History of a Document. New York: Oxford University Press, 2010.

Sekula, Allan. "The Body and the Archive." October 39 (1986): 3-64. doi:10.2307/778312.

Steyerl, Hito. “In Defense of the Poor Image.” E-flux Journal \#10, 2009. (November)1-9.

Schoedsack, Ernest B. "GRASS: The Making of an Epic." American Cinematographer, 02, 1983, 40-44,109-114, http://ezproxy.lib.ryerson.ca/login?url=https://search-proquestcom.ezproxy.lib.ryerson.ca/docview/196338280?accountid=13631. 